\title{
Strategies, Difficulties, and Written Communication in Solving a Mathematical Problem
}

\author{
Estratégias, Dificuldades e Comunicação Escrita na Resolução de Um \\ Problema Matemático
}

\author{
Letícia Gabriela Martins* \\ ORCID iD 0000-0002-1529-2830 \\ Maria Helena Martinho** \\ ORCID iD 0000-0001-5697-1568
}

\begin{abstract}
In an age where we live surrounded by technology, it is increasingly important to develop capabilities that differentiate us from "machines". The habit of solving problems can help us develop some of them, including the ability to solve problems, and stimulate critical thinking. It is, therefore, important to propose tasks of a diverse nature in the classroom, and to invest more in mathematical problem-solving by students. For students to solve those problems, it is essential that they know different strategies to use and it is necessary that the teacher can identify the difficulties experienced by students in solving mathematical problems, so the teacher can help students overcome them. This article aims to identify the strategies students use to solve a problem, acknowledge the difficulties students experience, and characterize students' written communication in their answers. To achieve these objectives, the answers to a mathematical problem which was solved by students of three 12th grade classes were collected and analyzed. In the resolutions analyzed, the strategy students used the most was the construction of schemes/figures. Regarding the difficulties, they were felt more at the level of information selection, as the students tended to add data that were neither in the statement nor could be deduced from it. Finally, when communicating their answers in writing, over half of the students did it with a high level of clarity, and the most frequently used type of justification was the exclusive use of schemes. In addition, the type of representation most used by the students was iconic representation.
\end{abstract}

Keywords: Problem Solving. Strategies. Difficulties. Written Communication. High School Education.

\section{Resumo}

Numa era em que vivemos rodeados de tecnologia, cada vez mais se torna importante desenvolvermos capacidades que nos diferenciem das "máquinas". O hábito de resolver problemas pode ajudar a desenvolver algumas delas, nomeadamente a própria capacidade resolver problemas e ainda estimula o pensamento crítico. Por isso, torna-se importante propor tarefas de natureza diversa na sala de aula, e investir cada vez mais a resolução de problemas matemáticos por parte dos alunos. Para que os alunos os resolvam, é fundamental que conheçam diferentes estratégias às quais podem recorrer e, além disso, é necessário que o professor consiga identificar as dificuldades que os alunos sentem ao resolver problemas matemáticos, para que possam ajudar os alunos a ultrapassá-las. Neste artigo, pretende-se identificar as estratégias utilizadas pelos alunos na resolução de um problema, reconhecer as dificuldades sentidas pelos alunos e caracterizar a comunicação escrita dos alunos na apresentação das suas respostas. Para responder a esses objetivos, foram recolhidas e analisadas as resoluções de um problema

\footnotetext{
* Master in Teaching Mathematics in the 3rd cycle of basic education and in secundary education from the University of Minho (UM). PhD Student in Educational Sciences, specialty in Mathematics Education, and researcher at CIEd, University of Minho (CIEd-UM), Braga, Portugal. E-mail: lgb.martins@ @ hotmail.com.

${ }^{* *} \mathrm{PhD}$ in Education, Didactics of Mathematics, University of Lisbon (UL). Assistant Professor, CIEd, University of Minho (CIEd-UM), Braga, Portugal. E-mail: mhm@ie.uminho.pt.
} 
matemático feitas em sala de aula por parte dos alunos de três turmas do $12 .^{\circ}$ ano, último ano da escolaridade obrigatória em Portugal. Nas resoluções analisadas, a estratégia a que os alunos mais recorreram foi a construção de esquemas/figuras. Já relativamente às dificuldades, estas foram mais sentidas a nível de seleção de informação, pois os alunos tiveram tendência a acrescentar dados que não estavam no enunciado, nem poderiam ser deduzidos a partir dele. Finalmente, ao comunicarem as suas respostas por escrito, mais de metade dos alunos fizeram-no com um nível de clareza alto, sendo que o tipo de fundamentação que utilizaram com mais frequência foi o uso exclusivo de esquemas. Além disso, o tipo de representação a que mais alunos recorreram foi a representação icónica.

Palavras-chave: Resolução de Problemas. Estratégias. Dificuldades. Comunicação Escrita. Ensino Secundário.

\section{Introduction}

In Portugal, problem-solving is an integral part of the curriculum of all compulsory school years in Mathematics. However, there are still students who are not used to solving problems. When the teachers propose mostly and almost exclusively the solving of exercises in their classes, students train the application of mathematics in specific contexts, memorizing problem-solving processes, but not developing the ability to reason and solve problems. This scenario is something we should avoid, as the school must prepare students for their future, both personal and professional, and this means enabling them to think critically, communicate their ideas correctly, and solve problems (OECD, 2018). Problem-solving contributes to the development of these capabilities. In this way, students will develop their problem-solving skills as well as learn how to communicate in writing, as they must record their reasoning so that it is clear to those who read it. Also, a problem usually leads to a discussion at the end of its resolution. Thus, problem-solving can also encourage students to discuss among themselves, exchanging ideas, defending them, and understanding peer ideas, which helps develop their critical thinking.

For teachers to feel more comfortable proposing problem-solving in the classroom, it becomes important to notice what a problem is, after all, something that will be clarified later in this article. In addition, it is important to know what strategies we can use to solve a problem, what kind of difficulties students may encounter, and how they will communicate their thinking in writing. After all this has been clarified, the responses of 12th graders, the last year of compulsory school in Portugal, will be analyzed through these three components: strategy, difficulty, and written communication. Thus, this study aimed at understanding how students would solve the proposed problem. In particular, we want to identify which strategies the students use, as well as to understand what kind of difficulties can be observed when students solve (or do not solve) the proposed problem. In addition, this study focuses on the written communication styles and strategies the students resort to make explicit their reasoning, and if 
this allows them to infer some sort of relationship between the clarity of the answers and their correctness.

\section{Concept of problem}

A problem can be seen as a situation that a person faces and requires resolution, for which it is not immediately known which way to go. This is the opinion of several authors, such as Kantowsi, Posamentier and Krulik. More generally, not focusing on teaching and mathematics, Kantowski (1980) states that the knowledge that an individual has can be used to find a new way to solve a problem that arises. Furthermore, Posamentier and Krulik (1998) argue that our actions, thoughts, and reasoning are usually based on our previous experiences. This influences the way we "tackle" a certain problem. For Pólya (1981), solving a problem means finding a way to overcome a difficulty or obstacle, trying to achieve a goal that seemed at first unattainable.

For some Portuguese authors, we are facing a problem when we have a well-defined objective, but there is a barrier that prevents us from obtaining a solution immediately (PIRES, 2001; PALHARES, 1997). Ponte (1992) indicates that a problem is a task for which the student does not have a previously studied method to solve it, but in which one must strive to reach the desired solution. This author also distinguishes problem from exercise, concepts that are often confused, referring that the resolution of an exercise only involves applying a previously known method, while in solving a problem the student has to search for the method in order to advance in the resolution. Cotic and Zuljan (2009) also add that a task can be seen as a problem for one person, but a routine exercise for another. This is because when the situation presented to us is already familiar and we already know which strategy to use, then it becomes a routine task, not a problem. But for someone who has never faced a similar task, it can indeed be a problem (COTIC; ZULJAN, 2009). So, it is possible to have a task that is both a problem and an exercise, such as the task with the following statement, presented by Lester (1987):

Tom and Susan went to their grandparents' farm and saw some chickens and pigs in the barnyard. Tom said he saw 18 animals in the barnyard. Susan agreed with him and added that she counted 52 legs in all. How many chickens and how many pigs were in the barnyard? (LESTER, 1987, p. 33)

This task can be considered a problem and an exercise, depending on who will solve it. According to Ponte (2005), if a statement of this kind is presented to a student in the primary education, we will be facing a problem. But if it is presented to a secondary school student, who has already mastered the use of systems of equations, this will be nothing more than an exercise. 
For the authors of this article, a problem will be assumed to be a task that is intended to be solved but for which no prior resolution method is known.

\section{Difficulties in problem-solving}

To develop certain skills, we need to recognize and identify our difficulties to overcome them. In teaching, it is essential to detect these difficulties so that new learning can occur. In addition, difficulties can demotivate or lower self-confidence, so it is necessary to detect and face them so that they can be overcome. In this way, the person can become more involved in solving a problem, more willing to do so, and more confidence in their knowledge and skills.

The adequacy of solutions to real situations and persistence are two aspects to be aware of in the students' attitude (D'AMBRÓSIO, 1989). For this author, students are so used to constantly dealing with the more formal side of mathematics that they lose self-confidence in their own mathematical intuitions. For this reason, a difficulty present in the students when solving problems is the adequacy of the solution to a real situation. Another difficulty is the lack of persistence, which is often motivated by the excessive habit of solving exercises only. It is quite common for a student to give up when faced with a mathematical problem, justifying the fact that he has not learned how to solve that kind of question (D'AMBRÓSIO, 1989). This is because the student cannot immediately understand which resolution process to use.

Not referring to difficulties, but obstacles, Sternberg (1998) indicates three problemsolving obstacles, which may appear separately or simultaneously: mental sets and fixation, functional fixedness and negative transfer. The first, mental sets and fixation, appears when we are stuck with a strategy that has worked in another situation, but that does not work on the problem before us and is therefore "fixated" on using that strategy and cannot find another. The second, functional fixedness, appears when we do not know how to apply knowledge learned in other contexts to new contexts. That is when we have access to various tools but cannot figure out which one to use in that situation. The third, negative transfer, appears when previous knowledge is not well understood. When this is the case, new learning is compromised as it will be more difficult to acquire and store new knowledge.

Another set of difficulties in solving mathematical problems is presented by Tambychik and Meerah (2010). These authors enumerate five difficulties based on mathematical and problem-solving skills, related to numbers, arithmetic, information, language, and visualspatial. The number fact skill is essentially related to the most elementary mathematics, learned mostly at the beginning of compulsory education. The term arithmetic skill, on the other hand, 
refers to the necessary precision throughout a mathematical development. As for the information skill, it is the ability to extract information and the relationship established between concepts, and the ability to translate a problem into a mathematical condition. Directly related to this is the language skill, which allows to decode mathematical terms and understand what the relevant information is to be removed. Finally, the visual-spatial skill, which is the ability to see the abstract part of Mathematics, at the level of geometric concepts, or at the level of manipulation of geometric shapes, or at the level of the notion of space. Without these wellworked skills, the authors argue that there is a greater possibility of making mistakes and confusions along the problem-solving process.

Other difficulties are listed by Phonapichat, Wongwanich and Sujiva (2013). These authors indicate three difficulties students may experience when solving problems. The first is the difficulty of understanding the problem, either in its entirety or only in certain parts. The second is related to reading, information selection and organization, in order to be able to translate words into mathematical symbols. The third refers to the students' lack of interest, which may be due to the extent of the problem or its complexity, which is a demotivating factor. Meeting these difficulties, Siniguian (2017) lists four common difficulties when solving mathematical problems: lack of comprehension, lack of strategy knowledge, inability to translate the problem into mathematical form, and inability to use the correct mathematics.

\section{Problem-solving strategies}

Some of the authors who indicate lists of difficulties that can be felt when solving a problem mention some difficulties that may be associated with strategies. These difficulties arise due to limited knowledge of strategies that can be used by those solving the problem. But what are strategies? According to Biddlecomb and Carr (2011), a strategy is a set of actions, mental or physical, designed to solve a particular problem. These authors refer that these strategies can be taught or simply appear spontaneously. Strategies can still be seen as "tools that might be used to discover or construct the means to achieve a goal" (BILLSTEIN; LIBESKIND; LOTT, 2007, p. 5). It is important for students to know the different strategies they have at their disposal, even if they only internalize them properly after they have used them on a particular problem and see that this has enabled them to reach the solution successfully (KLINGLER, 2012). Let's look at what strategies students can use when solving problems.

The list of strategies proposed by Lopes (2002) includes the following basic categories: making a model; making a table; trying, checking, and reviewing; simplifying; eliminating; 
finding patterns. In this nomenclature, we are making a model when we resort to an "equation, algorithm, formula, scheme, sketch, drawing, diagram"1 (LOPES, 2002, p. 24). Making a table involves drawing a graph or a chart. As for trying, checking, and reviewing, this strategy is also known as trial and error, and it is a method of thinking through possible solutions, and trying to figure out if they obey the problem information and its purpose. In the case of simplifying, it includes breaking down the problem into simple problems or even working from end to beginning, starting by taking the problem goal and working until it gets to the beginning, that is, what is given. The eliminating strategy consists of making a list of possible solutions based on the problem information, and we will eliminate elements of that list that are impossible in the context presented. This strategy, while similar to trying, checking, and reviewing, differs from it because the list is made right from the start when we are eliminating, while in the other we are launching one hypothesis, checking if it is possible, and if not, we launch another hypothesis, and so on until reaching a possible hypothesis. Finally, finding a pattern involves looking at the data provided and understanding if there are any patterns that can be used to achieve the correct answer more quickly.

Novotná et al. (2014) refer to seven possible strategies, some of which are common to the previous ones: analogy strategy, guessing - checking - revising, systematic experimentation, problem reformulation, solution drawing, working backwards, using graphs of functions. Two of these strategies, analogy strategy and working backwards, resemble Lopes' simplifying strategy. On the other hand, guessing - checking - revising meets trying, checking, and reviewing from the previous list. As for systematic experimentation, it consists of doing successive experiments - first applying an algorithm that we hope will help us solve the problem, then systematically changing the algorithm values until we find the right solution. The problem reformulation strategy consists of, for example, translating the problem into mathematical language, or from mathematical to verbal language. For solution drawing, as the name implies, make an illustrative drawing of what is described in the problem statement. To finish the list, we have using graphs of functions, strategy that consists in drawing the graphs of possible functions present in the problem statement.

With a slightly larger list, Billstein, Libeskind and Lott (2007) refer to the following problem-solving strategies: looking for a pattern, examining a related problem, examining a simpler case, making a table, identifying a subgoal, guessing and checking, working backwards, using indirect reasoning, using direct reasoning, writing an equation. Some of these strategies

\footnotetext{
${ }^{1}$ Translation of the citation was made by the first author of this article. Original citation: "equação, algoritmo, fórmula, esquema, esboço, desenho, diagrama" (LOPES, 2002, p. 24).
} 
are in line with others in the previous lists, which have similar names. Of the ten strategies referred to by these latter authors, only the strategies identifying subgoal, using indirect reasoning, using direct reasoning, and writing an equation have slightly different characteristics and names from the previous ones. The identifying a subgoal strategy is to define small steps that allow us to solve the problem as a whole but are simpler to solve than trying to solve the initial problem directly. Regarding using indirect reasoning, this strategy goes through a reduction to the absurd, that is, starting by stating that the objective we want to reach is false, establishing a logical reasoning from there, and, along the way, finding something that is contradictory and that lead us to conclude that our initial proposition could not be false. An "opposite" strategy to this one is using direct reasoning which, as the name implies, consists of establishing logical reasoning that enables us to respond to the problem. Finally, writing an equation is a strategy that can be included in making a model (Lopes' nomenclature) and in problem reformulation (Novotná et al. nomenclature), as it translates the problem statement into a mathematical equation, which must be solved and leads us to the intended answer.

\section{Written communication}

Mathematical communication is strongly related to problem-solving and reasoning (NERIA; AMIT, 2004). Students should be able to analyze the problem, find the appropriate resolution method, and communicate these steps to teachers and colleagues (WINCHELT, 2009). The whole process of teaching and learning presupposes the existence of communication, whether through speech, gestures or writing, as communication is the main source of "human interaction and meaningful exchange" (STEINBRING, 2015, p. 282).

In this study, we focus on written communication, as writing is a very important tool when solving a problem. When the student writes their reasoning, they leave a record of their resolution process, which allows them to constantly review what they have thought and allows them to make a possible correction that could take them on a better "path" (FREITAG, 1997). In addition, writing requires the student to be clear in their discourse, structuring their reasoning, and making connections between their previous knowledge and the emerging new knowledge (PUGALEE, 2001). The fact that a student clearly writes their reasoning, justifying and properly explaining their resolution, gives them even greater support in presenting their ideas orally (BAXTER; WOODWARD; OLSON, 2005).

"Essentially, writing in mathematics is about communicating ideas with clarity and an appropriate level of detail to make these ideas understandable and traceable" (FREEMAN; 
HIGGINS; HORNEY, 2016, p. 282). Writing helps students relate different ideas that come to mind and consolidate their thoughts. In this way, students can analyze, compare, and synthesize information, which allows them to create a clearer view of their reasoning (CROSS, 2008). This is because, through writing, students can share their results, knowing that they must be written precisely and clearly, so that they are well understood by those who read (FREEMAN; HIGGINS; HORNEY, 2016). These authors further emphasize that mathematical reasoning must be logical and solid, but written communication must also be coherent and equally consistent.

Casa et al. (2016) identifies four types of mathematical writing: exploratory, informative/explanatory, argumentative, and mathematically creative. The exploratory type has as main purpose "writing mathematically to personally make sense of a problem, situation, or one's own ideas" (CASA et al., 2016, p. 6). The second type, informative/explanatory, has the purpose of describing, using definitions or representations, and to explain, namely, the strategies used to solve a certain problem and the reasoning process behind it. The third type, argumentative, aims at building the necessary arguments to support reasoning and, simultaneously, "Students may use mathematical writing to reason about and communicate critiques of others' arguments" (CASA et al., 2016, p. 13). Finally, the mathematically creative qualifier refers to a type of writing which main objective is to develop original ideas and flexible thinking. Although these authors target at the first levels of education, the types that Casa. (2016) refers to can also be useful for older students. All of these types support the idea that "Mathematical writing is a tool that can further students' reasoning and communication" (CASA et al., 2017, p. 7).

This research aims to characterize students' written communication when solving problems. For this, it is necessary to establish some criteria. Santos and Semana (2014) elaborated a list with three points to consider when analyzing written communication: the interpretation of the task goal, the justifications presented, and the representations used. The interpretation of the task goal is divided into two parts: the goal statement and the language used. The goal statement consists of identifying the task objective and completing the information gathered. The language used is to analyze whether the goal statement is transcribed or rewritten using the words themselves, and the accuracy of the language. The justification presented refer to the type of justification and its correctness and completeness. The authors present the following types of justification: vague (unclear or uninformative justification), rule (justification with exclusive use of rules, algorithms, or definitions), procedural (justification of what is done at a given stage, but without explaining its validity) and relational (justification 
of a step validity, including or not the justification of what is done in a given step, giving room for a relational understanding). Lastly, the representations used consider the types of representation and their accuracy and completeness. Santos and Semana (2014) indicate three types of representation: verbal language (natural language, made by students' words and mathematical terminology), iconic representation (use of schemes or drawings) and symbolic representation (using numeric symbols and/or algebraic).

This last point is also highlighted by Neria and Amit (2004). These authors indicate another nomenclature for the type of representations that can be used when solving problems, but which have common points with the representations of Santos and Semana (2014). These representations can be algebraic, numeric, verbal, or graphic. Algebraic representations are used when the explanation is represented by an equation or function. Numerical representations are used when the explanation is represented by calculations. Verbal representations are seen when the explanation is written in words. Graphic representations are used when the explanation is represented by diagrams, graphs, or other pictorial illustrations.

Martinho and Rocha (2017) used the Santos and Semana (2014) model in their study, with some changes. This model was divided into three topics: problem comprehension, answer justification, and representations used. In the topic related to the problem comprehension, Martinho and Rocha (2017) ask whether the student shows that they have understood what is being asked, if they have gathered the information well and completely, and if they have transcribed the problem objective and information or if they have been rewritten in their own words. The topic of answer justification is divided into two points: the level of justification in which the correctness of the answer, the clarity, and the completeness are embedded -and the justification type. In this justification type, the authors reveal affinities with the justification types of Santos and Semana (2014). Martinho and Rocha (2017) have the following types: vague, unclear or uninformative; exclusive use of rules, algorithms or definitions; resorting to experimentation; procedural description (in which it is explained what is done but not justified why it is valid); relational justification (in which it is explained what is done and justified why it is valid). Finally, in the topic of representations, the representations indicated by Santos and Semana (2014) are repeated.

For this article, students' written communication will be characterized according to the justification of their answers and the representations they use. Contrary to what happened in the models of Santos and Semana (2014) and Martinho and Rocha (2017), problem comprehension will not be a characterization point of written communication, because it is a point that fits in the difficulties experienced during the resolution. If a student didn't understand the problem 
well or didn't collect the data properly, they have shown difficulties at this level. It becomes unnecessary, then, to reinforce this point again when we speak of written communication.

\section{Context and methodology}

To develop this study, problem resolutions were collected from pupils in three 12th grade classes of a Portuguese school at the end of April 2019, about a month before the end of the school year. These students, aged between 17 and 18 years old, attend a school located in an urban center, in a city on the northern coast of Portugal. The three classes had as their common variable the fact that they had the same teacher, and all attended the same curriculum in Mathematics. Two of these classes had 29 students and the third one had 27 students, and it was not usual for most students to solve problems in the classroom. All members of the class were confronted with two problems, which they had to solve individually, and had 45 minutes to do so. In this article, the results that will be presented result from the students' resolution to one of these problems. The problem proposed to the students for this study was called the "Greetings Problem", and it is stated in Figure 1.

We were eight people in the room. Gilberto greeted
everyone. Isabel greeted six people and Beta five. Gui
greeted four and Manuel three. Rogério greeted two people
and Alcina only one. Who did I greet?

\section{Figure 1 - Statement of the "Greetings Problem"} Source: Viana (2012, p. 96)

The problem chosen for this analysis proved to raise students' interest. The choice, however, was driven by a number of criteria: independence from the subject taught at the time of the study; familiar and simple but requiring some sort of structured reasoning from the students. In addition, through previous experience with other students, it was realized that the proposed problem would spark much discussion among students. We wanted the resolution of this problem to give them an opportunity of interpretation, reflection, and to express their ideas in written form, as well as to involve the students in an active discussion after the resolution attempt. We believe that by providing these experiences to students, we are contributing to the development of their critical spirit and ability to argue.

The data collection for this study was made by the researcher and first author of this article, being present at the moments when the students solved the proposed problems. After this collection, the same researcher analyzed the students' answers, identifying from there the strategies used by the students, the difficulties they felt and the way they communicate in 
writing. This research therefore follows a qualitative approach. The main characteristics of this type of research are that the research focus is on understanding what is derived from the data, the researcher has an active participation in collecting and analyzing the data, and the final product is very descriptive (MERRIAM, 2009). In addition, the data collected for this study are revealed in this article through images of student resolutions, which are expressed in words or drawings. According to Neuman (2014), these characteristics reinforce the fact that this research is inserted with a qualitative approach.

Data analysis was done through the content analysis technique. According to Stemler (2001), content analysis is defined as a technique to compress a text with many words in certain categories based on a number of coding rules. This author also adds that content analysis is a useful technique to look for patterns and trends in certain documents. For this study, this was exactly what we intend to: understand if there is any trend in the strategies used, in the difficulties observed, and in the way students write their answers.

For Esteves (2006), the term "content analysis" involves a set of techniques that can be used to treat information that was previously collected. This information, usually too extensive, is then reduced, by means of certain rules, in order to facilitate data understanding in a way focused on the objective that the researcher proposes to achieve (ESTEVES, 2006). These data, according to the author, can be of two types: invoked data (i.e. extracted from phenomena that happen independently of the researcher's action) and raised data (i.e. collected through actions explicitly requested by the researcher). The data considered in this research is the result from a request made by the researcher, and therefore classified as raised. The researcher asked the students to solve the problem, and the object of analysis was precisely the set of their resolutions, that is, data were collected according to what was requested by the researcher. The data were organized according to the strategies that the students used, the difficulties observed in their answers and the way they communicated in written form. This organization of data meets Bardin's comment on content analysis: that it "seeks to know what is behind the words on which it focuses"2 (BARDIN, 1977, p. 44). In this study, these "words" are the images with the students' resolutions, and the content analysis was used to understand everything that could be taken from them, within the objectives initially set.

Bardin (1977) also talks about three phases in content analysis: pre-analysis, material exploration, and treatment of results. The first phase, according to the author, corresponds to the moment when the objectives of the investigation are defined, the relevant documents for the

\footnotetext{
${ }^{2}$ Translation of the citation was made by the first author of this article. Original citation: "a análise de conteúdo procura conhecer aquilo que está por trás das palavras sobre as quais se debruça” (BARDIN, 1977, p. 44).
} 
analysis chosen, a first reading of the data made, and the indicators defined. After this preanalysis, we move on to the exploration of the material, which is nothing more than formally defining the decisions that were made in the previous phase. Finally, we enter the phase of treatment of the results taking care to correctly understand if the data is really significant and valid. This phase builds tables and graphs to help with data reading and allows to reach the following two points: guidance and questions that may give rise to new investigations, or the use of these results to draw theoretical conclusions.

It is around a categorization process that analysis procedures are often organized (BARDIN, 1977). This categorization process should lead to the construction of a system of categories, which will serve to analyze the information in order to facilitate content analysis (LIMA, 2013). This categorization can arise from two distinct paths: it can be a system created a priori, that is, the categories are created before analyzing the data and built based on previously known theory, or it can be a system created a posteriori, that is, categories are created as they appear in the data (BARDIN, 1977). In the case of the research reported in this work, the system of categories is divided into three main sets: the difficulties observed, the strategies used and the written communication. This system was created mainly a priori, taking into account the theoretical framework already presented. However, some subcategories were added because we felt that none of those that had been pre-defined was adequate - some item concerned with the difficulties was missing.

The difficulties that will be considered a priori in this investigation are divided into four distinct levels: persistence, interpretation, information selection, and strategy. At the level of persistence, we include the difficulty of starting or solving the problem, as there are students who are able to start a problem-solving process but do not know how to finish it, eventually giving up. Difficulties in interpretation will be seen from two points of view: statement interpretation and result interpretation. The first focuses on understanding what is required and the problem data, while the second relates to the attribution of meaning to the solutions obtained, both in the problem context and in the real context. The level of information selection will be relative to the difficulty students may experience in collecting problem data. Finally, the difficulty at the level of strategy is present in both the strategy choice and its execution.

As one of the objectives of this investigation is to identify which strategies were used to solve a proposed problem, it is important to clearly define which list of strategies we will assume from now on. In this article, the strategies mentioned will be considered, such as trial and error, finding patterns, piecewise resolution, deduction, working backwards, making schemes or figures, making a table, and making a model. This was the list of strategies defined 
a priori for this study. Note that they are consistent with the literature, although appearing sometimes under different names.

Finally, regarding written communication, in order to make its characterization more structured, the following points will be followed:

a. Justification for the answer:

- Depending on the justification:

$>$ correctness

$>$ clarity

completeness

- Depending on the justification type:

$>$ vague or uninformative

$>$ exclusive use of rules, algorithms or definitions

resorting to experimentation

$>$ procedural (justification of what is done in one of the steps, without explaining its validity)

relational (justification of a step validity)

b. Representations used:

- verbal language

- iconic representation

- symbolic representation

With these well-defined criteria, it becomes simpler to understand the characterization that will be made regarding students' written communication when solving the problem under study.

\section{Results}

This problem caused a stir in all the classes that participated in this data collection, as after solving it they discussed whether a greeting would be reciprocal or not. Does the fact that I greet someone means that they also greeted me? In fact, the problem was designed for the greetings to be something reciprocal by imagining, for example, that the greetings were shaking hands. If we did not assume that the greetings were reciprocal, the problem would not have a solution, since data would be missing. Thus, students who assumed that the greetings were not reciprocal invented data that was neither in the problem statement nor could be deduced from 
it, only to come to some conclusion. This was the most obvious barrier that prevented many students from reaching the correct solution. This obstacle helped that of the 85 students who participated in this study, only 34 came to the right solution, and 3 to a partially correct solution. Let's see what strategies students used to solve this problem and what difficulties they felt.

\subsection{Strategies identified in problem-solving}

To solve this problem, the students used only four of the strategies on our list: finding patterns, deduction, making schemes or figures, and making a table. Of these four, the most widely used strategy was the making schemes or figures one, with more than $65 \%$ of the students using it, although they resorted to different schemes, as shown in Figure 2.

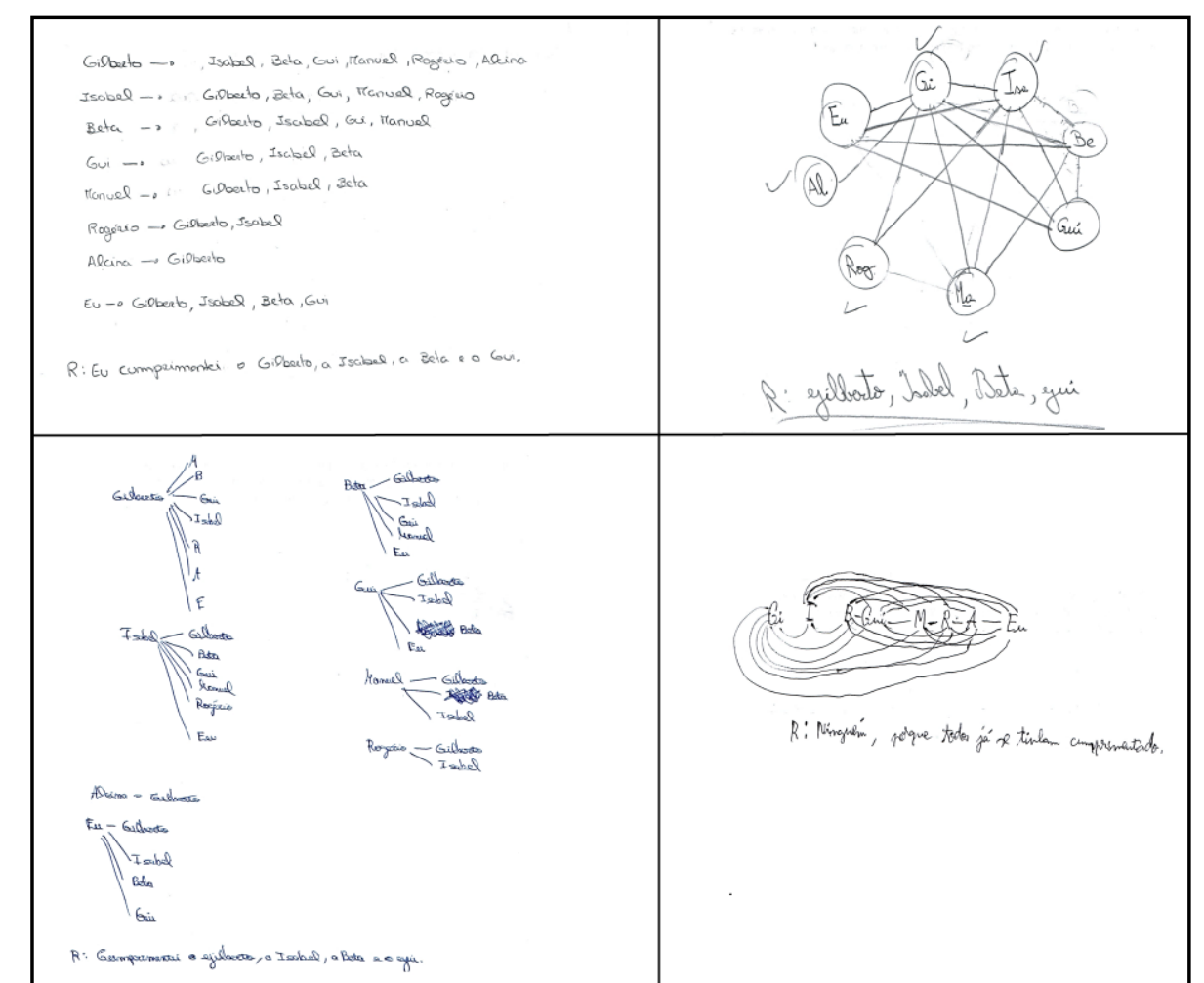

Figure 2 - Examples of four resolutions using the strategy of making schemes or figures Source: Research Data - Students A1, A2, A3 and A4 (2019)

The schemes made by the students were all similar to those presented in Figure 2, although in eight of the resolutions that resorted to this strategy, it was used at the same time with another: deduction in six of the cases and finding a pattern in the remaining two. One of the cases in which a scheme was used simultaneously with the deduction can be seen in Figure 3. 


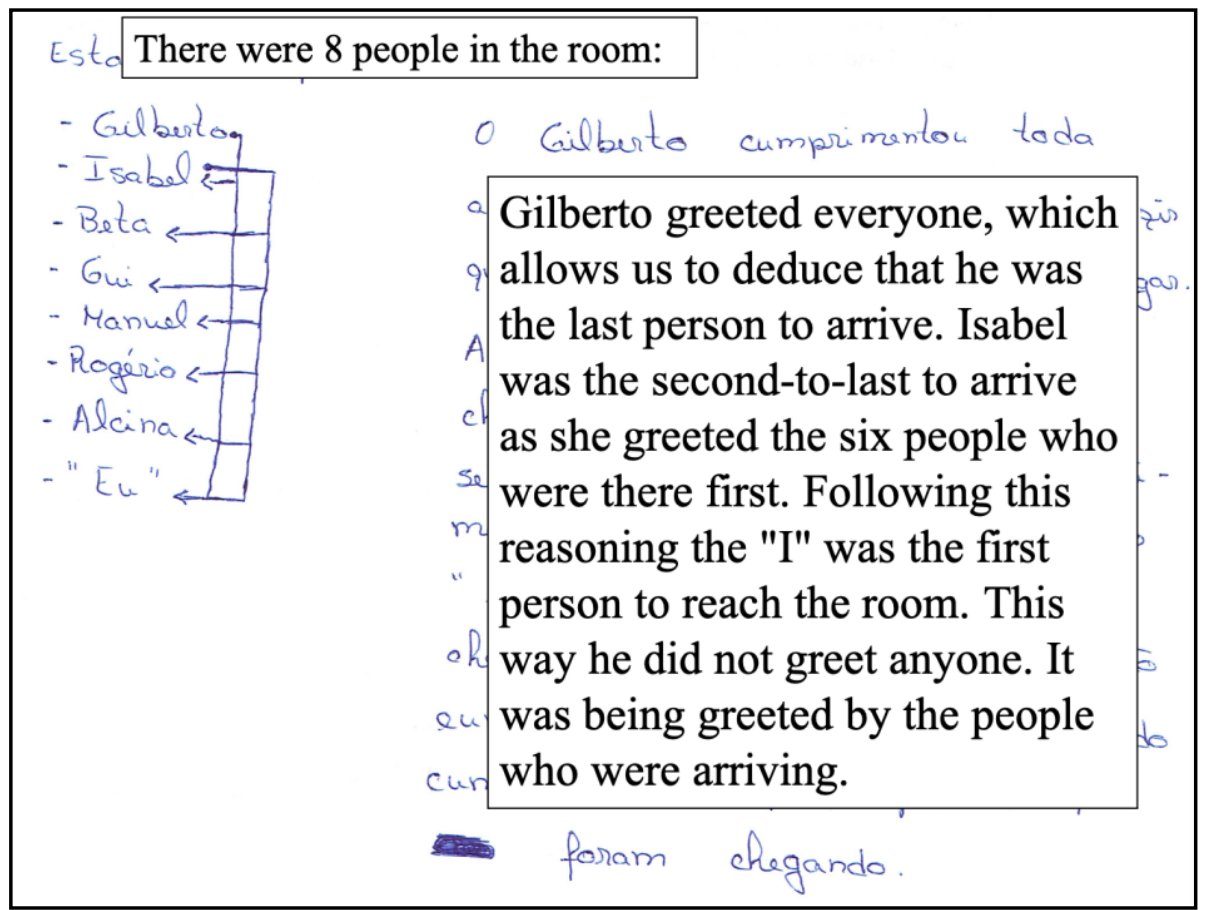

Figure 3 - Problem solving example using the strategies of making a scheme and deduction Source: Research Data - Student A5 (2019)

Deduction was the second most used strategy, although less than $30 \%$ of students used it. This strategy was used exclusively by 17 students. The remaining students who used it, 7 students, did it at the same time as the making schemes or figures strategy, as is the case with the resolution of Figure 3.

The search for a pattern, a strategy found in five of the resolutions, was a strategy used exclusively by three of these students. The two students who used the finding a pattern strategy in conjunction with another one, made them using the schemes or figures strategy. An example of this can be seen in Figure 4.

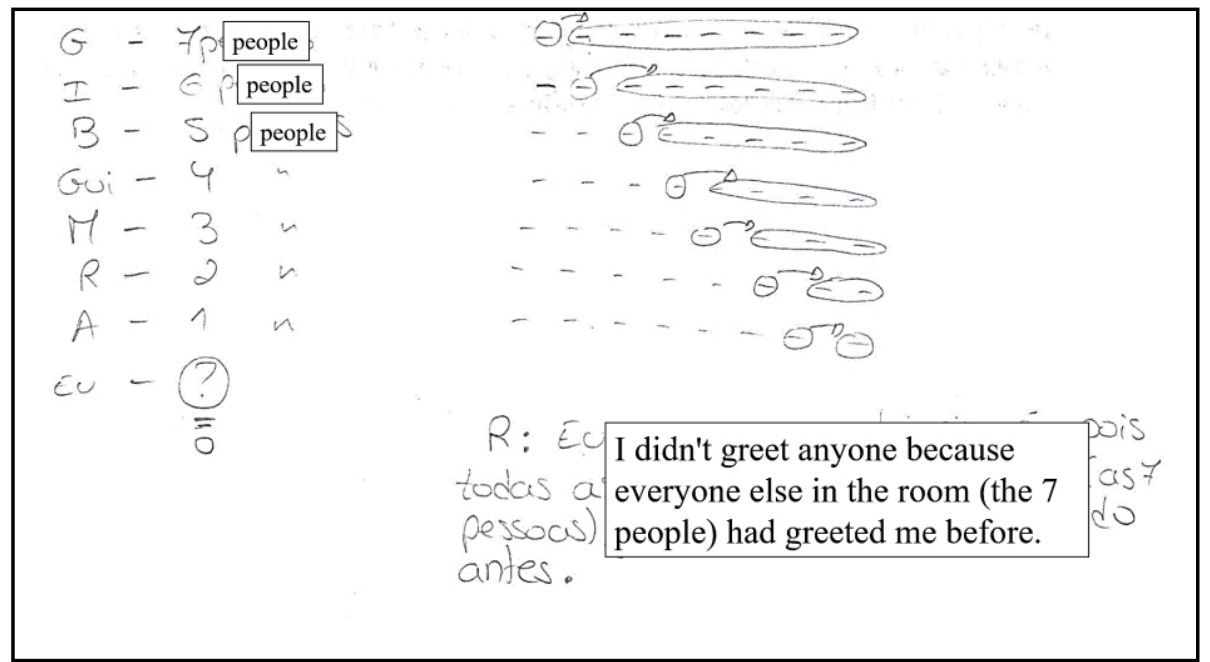

Figure 4 - Problem-solving example using a scheme and the search for a pattern Source: Research Data - Student A6 (2019) 
In resolutions where students were looking for a pattern, as in Figure 4, it becomes apparent that the fact that the statement contained the numbers $6,5,4,3,2,1$ in exactly that order influenced the students, considered that the logical reasoning would be to continue the sequence, answering that "I" would not greet anyone, since it would be the next number (0).

Lastly, another strategy that was also used was the construction of tables, which example we can see in Figure 5.

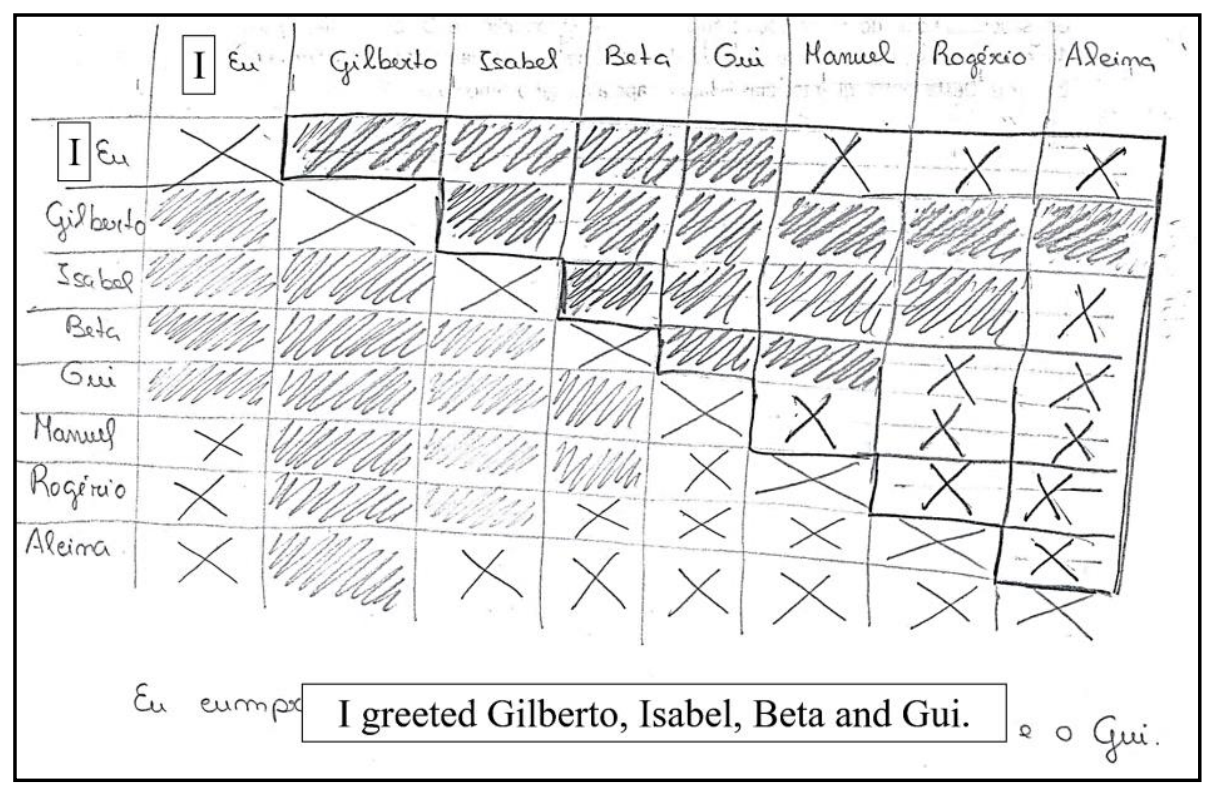

Figure 5 - Problem solving example using the construction of a table Source: Research Data - Student A7 (2019)

Making a table was the only strategy used exclusively by all six students who resorted to it. But while in the example in Figure 5 the answer to the problem is correct, using this strategy or any of the others does not guarantee students the right solution. In fact, regarding the strategy most used by students, construction of schemes or figures, the number of students who responded correctly and incorrectly, using this strategy, was approximately the same, as happened in the use of construction of tables. Regarding the deduction strategy, it was found that of 17 students who used it exclusively, 6 arrived at the correct answer, while 11 failed. This may be a small indicator that the deduction strategy may not be as effective for students in the context of this problem. In addition, regarding the finding a pattern strategy, none of the students who resorted to it were able to obtain the correct answer, which may indicate that it would be an inappropriate strategy for this problem. This is because, although students may use the same strategy, each will have their own unique difficulties, which can significantly change the response given by each student. Thus, it is necessary to see the difficulties experienced by these students. 


\subsection{Difficulties identified in problem-solving}

In analyzing the students' resolutions to this problem, some difficulties were detected, mainly in the information selection level. Recall that in the list of difficulties that would be considered in this study, the information selection level is broken down into two points: difficulty in collecting data and difficulty in organizing data. In resolutions to this problem, difficulties were encountered in both aspects. An example of the difficulty in collecting data can be seen in Figure 6.

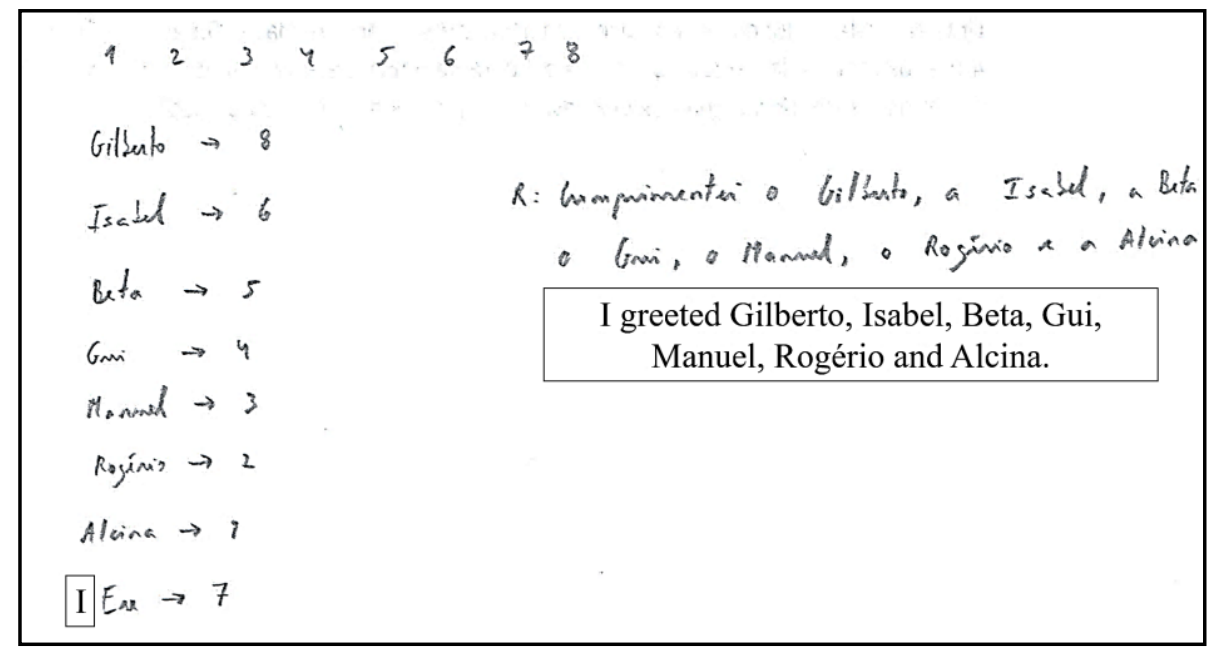

Figure 6 - Problem-solving example where we can see the difficulty in collecting problem data Source: Research Data - Student A8 (2019)

In Figure 6 we see that the student assumed that Gilberto had greeted 8 people, when 8 is the number of people in the room, which reveals a difficulty in collecting data. This difficulty was found in three other resolutions, all because they considered that Gilberto greeted 8 people instead of 7.

Regarding the difficulty in organizing the data, we can see it in Figure 7. 


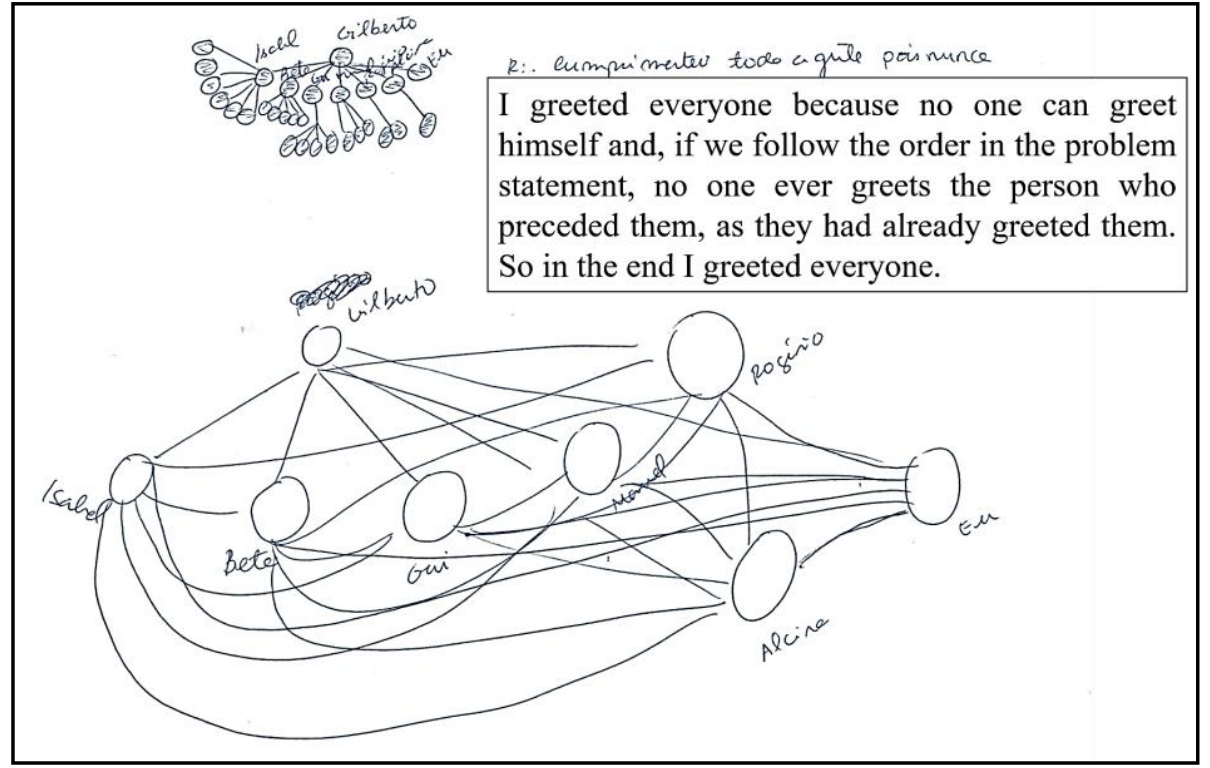

Figure 7 - Problem-solving example where we can see the difficulty in organizing problem data Source: Research Data - Student A9 (2019)

This difficulty was found in six resolutions, and all of them had schemes like this one. Students did not realize that by placing the problem data in such a scheme, they were altering the data. For example, in the case of Figure 7, we realize that there are seven "ways out" of the circle that represents Rogério, when there should only be two, since Rogério only greets two people. This confusion stems from the fact that students are assuming that the greeting is not reciprocal, which, as mentioned earlier, was a major impediment to getting students to the right solution.

Although the difficulties in the information selection level were initially divided into two points, when analyzing the answers to this problem, there was a need to add a new point. This new point refers to the difficulty that students have in restricting themselves to the problem statement data, assuming data that is not presented in the statement nor can be deduced from it. 


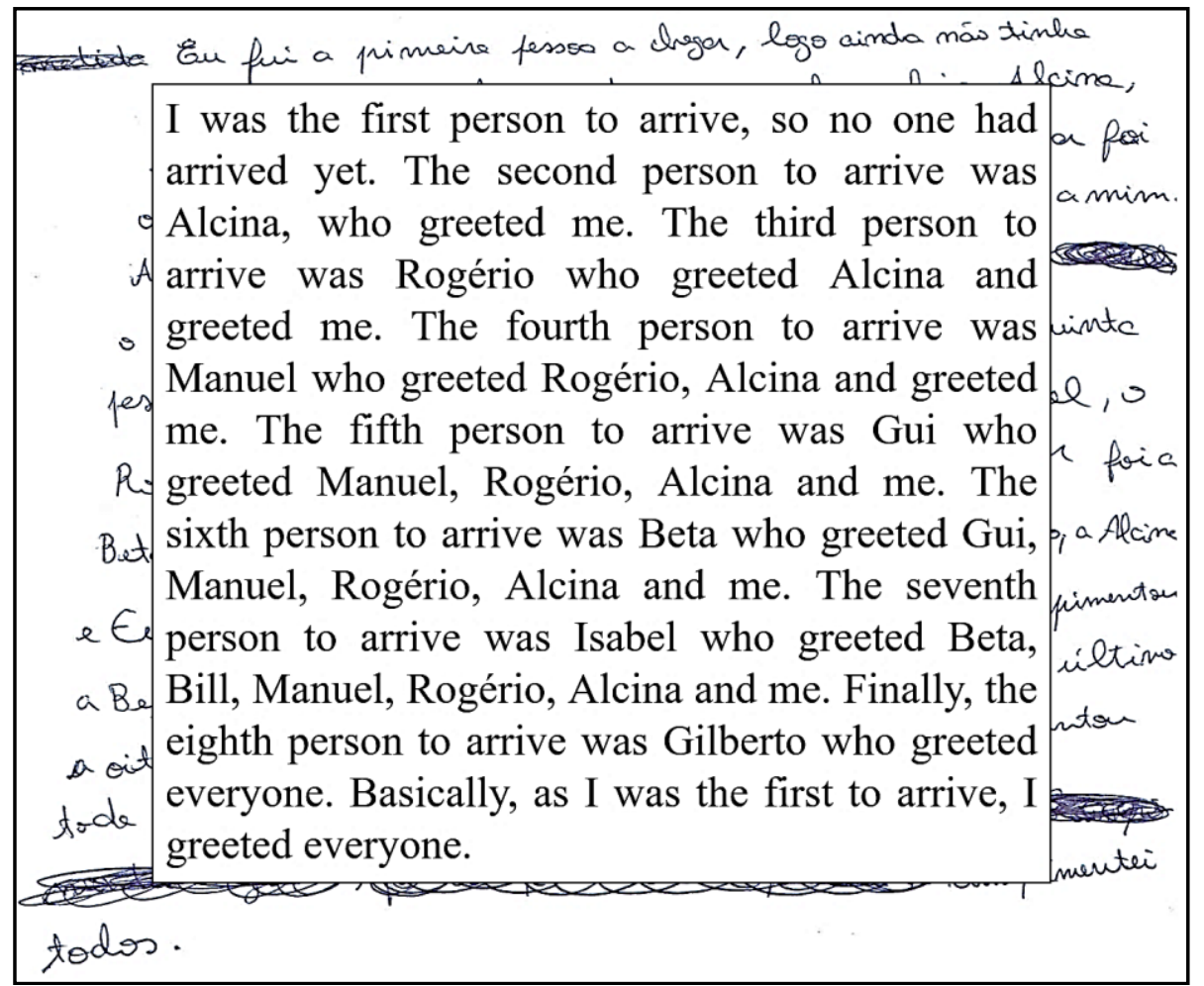

Figure 8 - Problem-solving example where we can see the difficulty in restricting to the statement data Source: Research Data - Student A10 (2019)

As can be seen from the answer, the student begins by indicating that "I was the first person to arrive", when at no point this is mentioned in the statement, or something that leads us to this conclusion. Twenty students revealed this difficulty, all by making similar statements to what we find in Figure 8, assuming they were the first to arrive in the room and therefore other people would greet them as they arrived. And it is with this kind of assumption that another difficulty is later observed, which is also absent from our initial list. This difficulty is the lack of coherence and we can see an example of this difficulty in Figure 9.

$$
\begin{aligned}
& \epsilon u \rightarrow 9^{-} \text {a chegar, 1st to arrive; didn't greet anyone } \\
& \text { Alcina } \rightarrow 2 ª \text { cheg an", só on 2nd to arrive; just greeted me } \\
& \text { Rogénio } \rightarrow 3^{-} \text {achegon, } 2 \text { pessoas } 3 \text { rd to arrive; } 2 \text { people } \\
& \text { Manuel } \rightarrow 4^{2} \text { < chogon, 3pess or 4th to arrive; } 3 \text { people } \\
& \text { Gui } \rightarrow 5^{2} \text { a clegon, } 4 \text { pessow } 5 \text { th to arrive; } 4 \text { people } \\
& \text { Beta } \rightarrow G^{2} \text { a chegan, } 5 \text { pessoan 6th to arrive; } 5 \text { people } \\
& \text { Isabel } \rightarrow 7^{\circ} \text { a chegan } 16 \text { persoon } 7 \text { th to arrive; } 6 \text { people } \\
& \text { Gilbento } \rightarrow 8^{\circ} \text { a chegan, } 7 \text { 8th to arrive; } 7 \text { people (everyone) }
\end{aligned}
$$

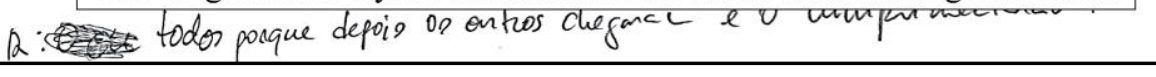

Figure 9 - Problem-solving example where we can see the difficulty in being coherent Source: Research Data - Student A11 (2019) 
In the Figure 9 resolution, we see that the student begins by mentioning that he was the first to arrive and, therefore, did not greet anyone. And, in his final answer, he says he greeted everyone because the others came in and greeted him. Throughout his reply, he implies that the greeting is not something reciprocal, since he assumes that Alcina, as she was the second to arrive, would only greet him, and Rogério would greet him and Alcina, and so on. However, in the end, the student assumes that the greeting is something reciprocal, which contradicts what he says earlier because, in this case, Alcina could not have greeted him and be greeted by Rogério, so it would make a total of two greetings when in the statement we read that Alcina greets only one person.

Another level at which difficulties were encountered, albeit less, was the level of strategy. Four students had difficulty choosing a strategy that would allow them to solve the problem. An example of this is in Figure 10.

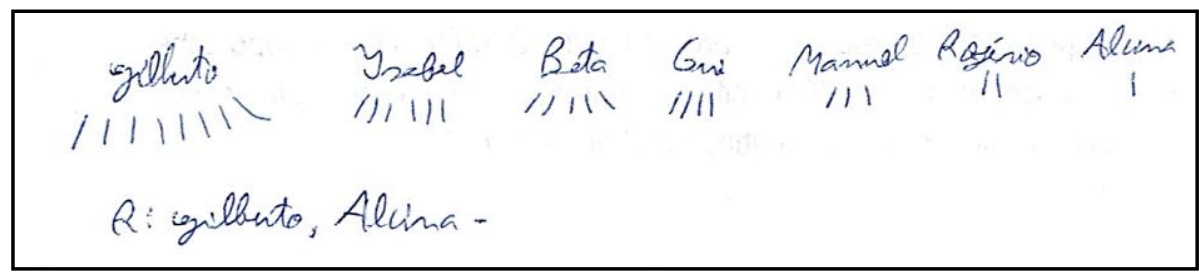

Figure 10 - Problem-solving example where we can see the difficulty in choosing a strategy Source: Research Data - Student A12 (2019)

The student tried to make a scheme that translated the data present in the statement but could not develop anything further because he could not establish a strategy that would allow him to develop a reasoning. But within the level of strategy, there were also cases of difficulties in executing the strategy in three resolutions. Let's look at Figure 11.

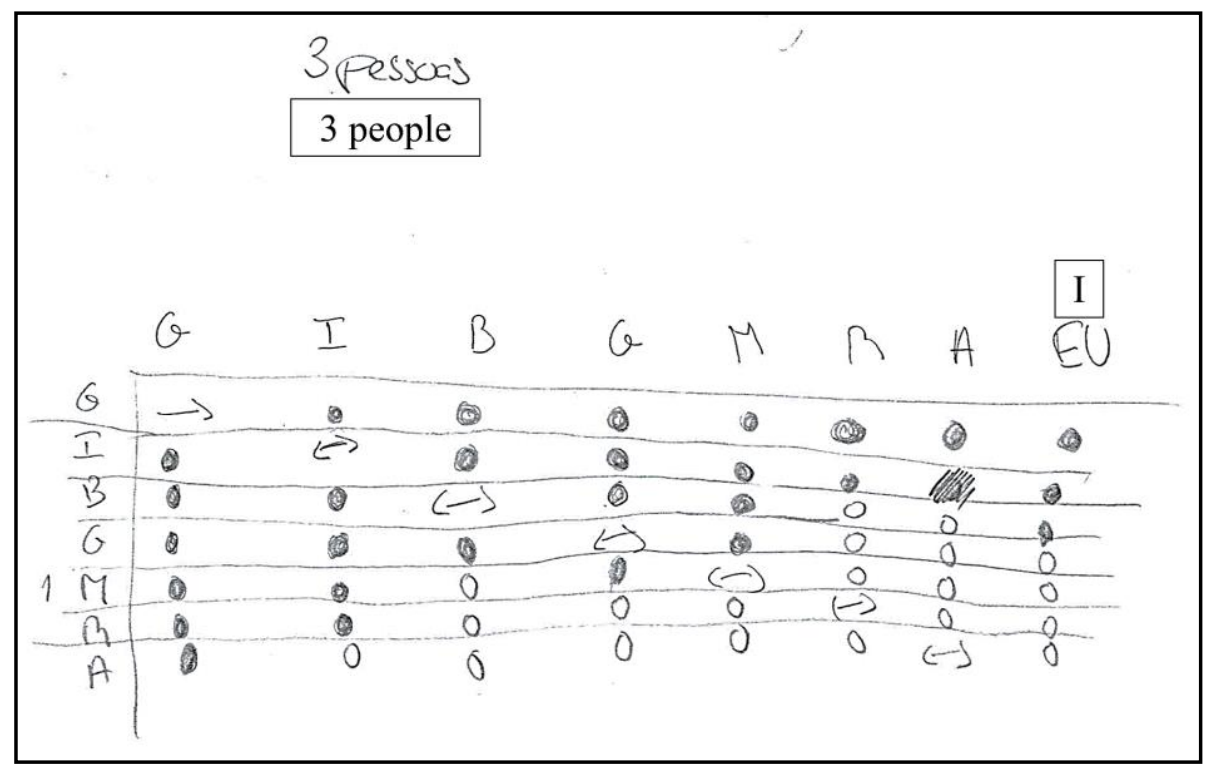

Figure 11 - Problem-solving example where we can see the difficulty in executing the strategy Source: Research Data - Student A13 (2019) 
In the Figure 11 resolution, we noticed that the student resorted to the construction of a table to solve the problem. However, he did not realize that he made a mistake in completing the column regarding the greetings made by Manuel, as Manuel only greeted three people and, in the student's resolution, there are four black balls instead of three in Manuel's column. Thus, the line regarding Gui's greetings was poorly filled, as the four black balls in this line should be in Gilberto, Isabel, Beta, and Eu (this means "I", in portuguese).

Finally, we saw difficulties in the persistence level. Two students did not start solving the problem and four were unable to complete their answer. We can see an example of this last difficulty in Figure 12.

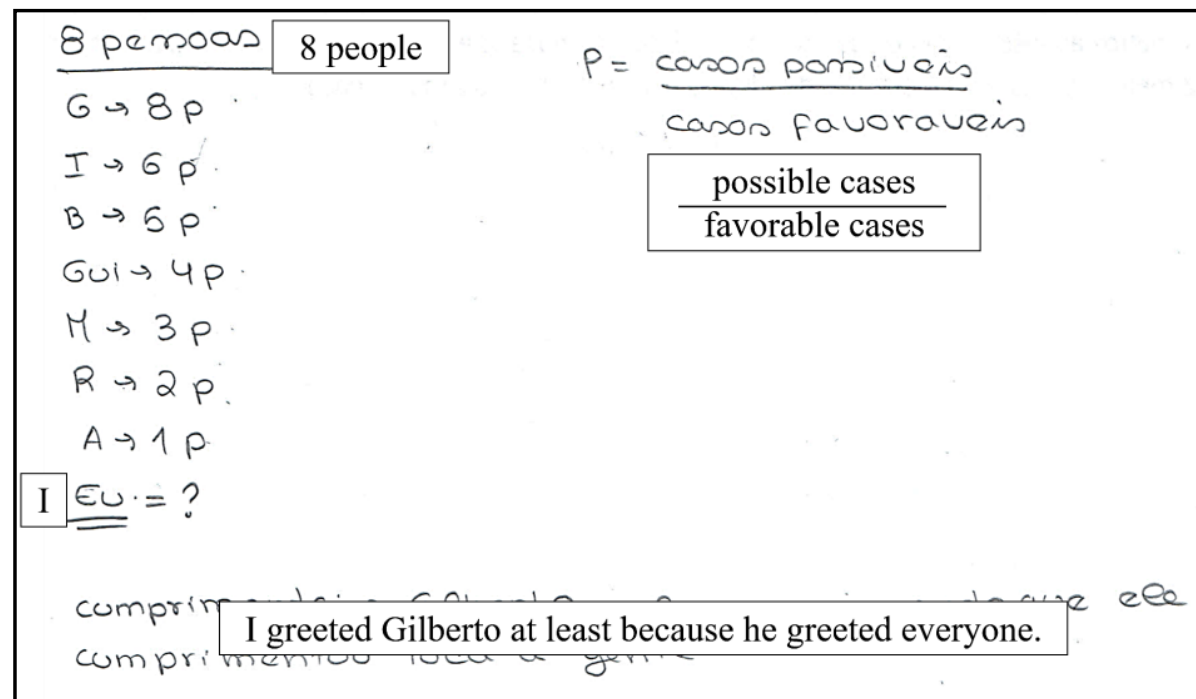

Figure 12 - Problem-solving example where we can see the difficulty in completing the problem resolution Source: Research Data - Student A14 (2019)

In the Figure 12 resolution, the student states that he is sure that the "I" greeted at least Gilberto, since he greeted everyone, but cannot conclude the reasoning in order to understand if there were more greetings and, if so, who greeted who.

\subsection{Written communication on problem solving}

Written communication will be characterized according to the answer justification and the representations used. Starting with the given answer justification, and that justification level, the aspects related to the correctness, clarity, and completeness of the answers must be seen. This last component, the completeness of the answer, was verified in all responses to the problem and no incomplete answers were found. 
Regarding the correctness, as mentioned above, of the 85 students who participated in this data collection, only 34 obtained the correct solution, and 3 registered a partially correct solution. In Figure 13 we can see an example of one of the partially correct answers.

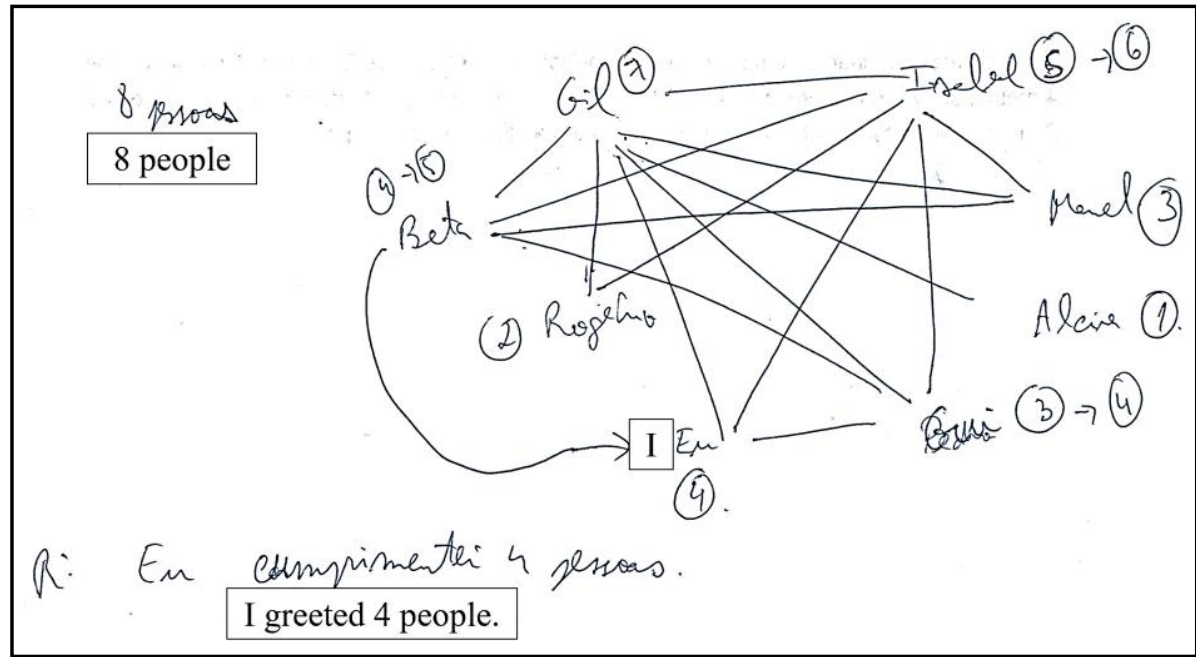

Figure 13 - Problem-solving example with a partially correct answer Source: Research Data - Student A15 (2019)

The three students with partially correct answers had the same solution: they greeted four people. In fact, the number of people was four, but the question of the problem was "Who did I greet?". Therefore, the answer should be with the name of the people, not just the number of people greeted by "me".

Of the remaining 48 students, we have already seen that two had difficulty initiating problem-solving and four had difficulty solving it, meaning that six students did not reach a solution. Of the other 42 answers, 25 had the solution "I did not greet anyone" (Figures 3 and 4), 11 answered "I greeted everyone" (Figures 6 to 9), two indicated that "I greeted everyone except Gilberto", two others replied that "I greeted three people" (Figure 11), there was still a response indicating "Gilberto and Alcina" (Figure 10) and finally another response with only "Gilberto".

Regarding the clarity of the answers, it was necessary to distinguish three levels of clarity: low, medium, and high. Within the low level are the answers where we cannot understand the reasoning established by the student, because it is not well explained. Of the total responses collected, about $21 \%$ of students responded with a low level of clarity, as seen in the example in Figure 14. 


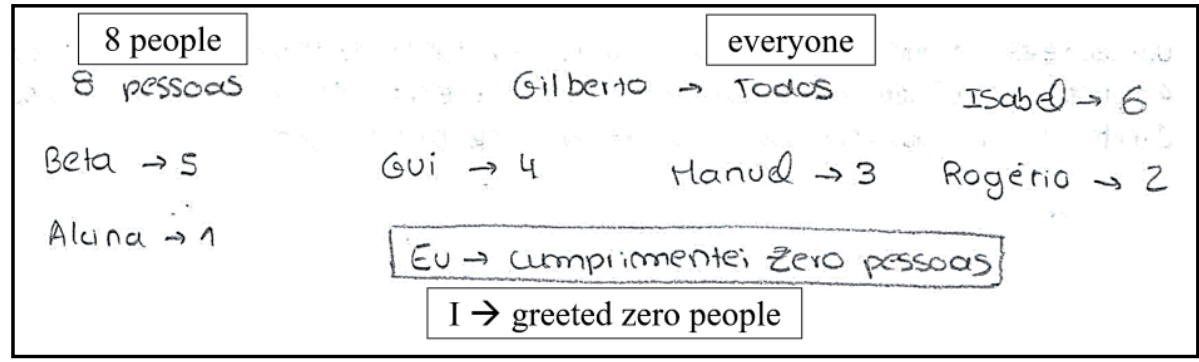

Figure 14 - Problem-solving example with a low level of clarity Source: Research Data - Student A16 (2019)

The student whose answer is illustrated in Figure 14 does not spell out any kind of reasoning, so it makes it impossible for the reader to understand how he thought, leaving his answer unclear to the reader. At a medium level of clarity, the percentage of students at this level was similar to that of the low level, and we can see a response from this level in Figure 15.

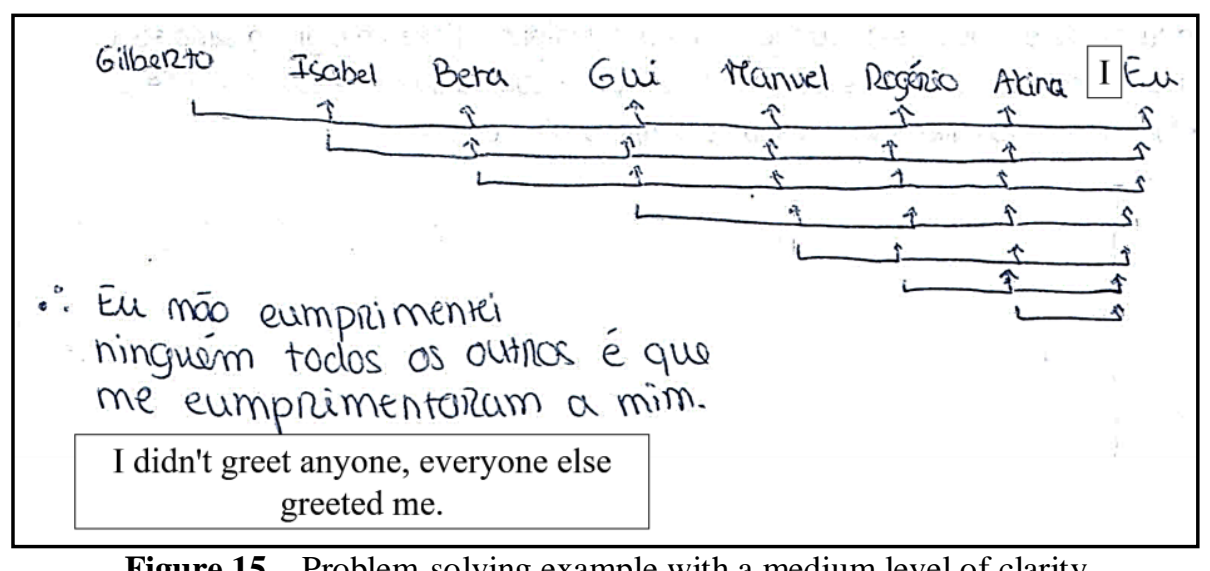

Figure 15 - Problem-solving example with a medium level of clarity Source: Research Data - Student A17 (2019)

In this last answer, we can already notice some reasoning. We noticed that the student put the names of the people in the problem and placed arrows that apparently indicate the greetings that were made, and who greeted who. However, his scheme needs to be further explained. Although we understand what the student thought, it could be better explained and clearer to those who are not so into the problem.

High level of clarity was the most verified, with 45 responses at this level. We can see an example of one of them in Figure 16. 


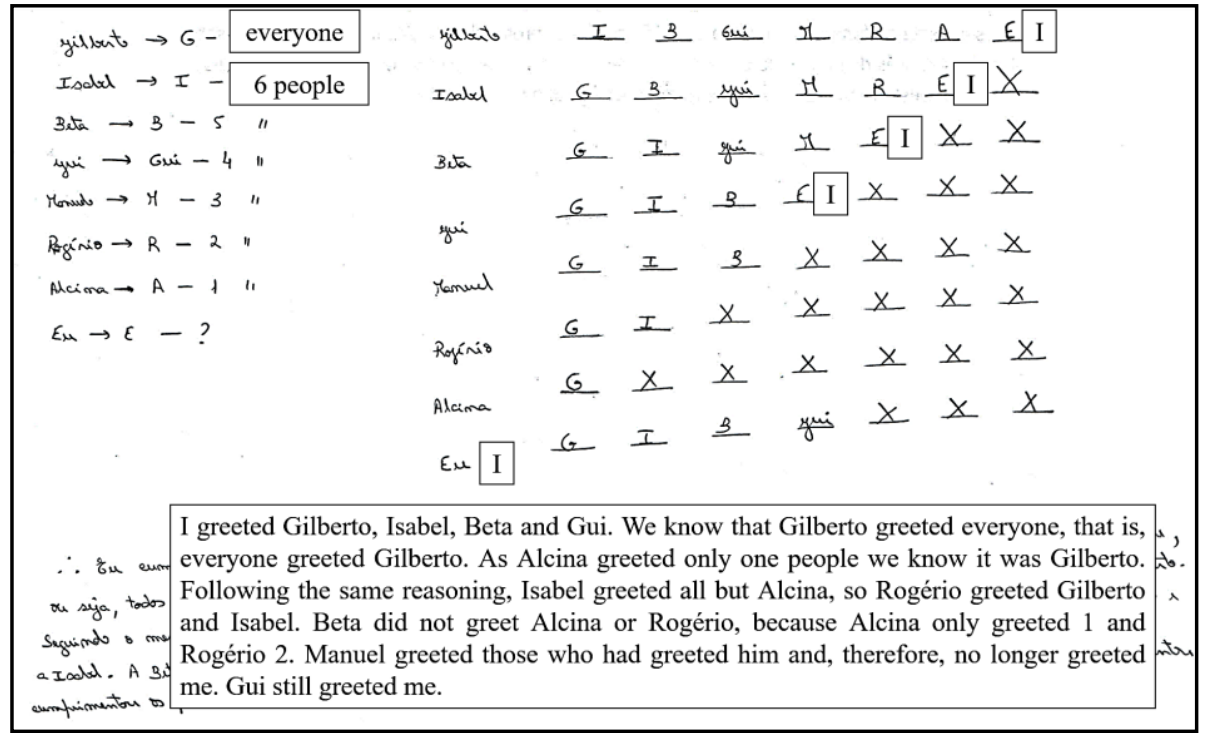

Figure 16 - Problem-solving example with a high level of clarity Source: Research Data - Student A18 (2019)

Contrary to what happens in the Figure 15 example, in Figure 16 we understand the reasoning made by the student, as she explains it through the scheme she elaborated and by writing her answer.

As expected, most of the correct answers, more than $70 \%$ of these, had a high level of clarity. However, in the answers considered incorrect, there was no pattern regarding clarity. Among the answers considered incorrect, the number of resolutions categorized with a high and low level of clarity was very similar, with approximately $37 \%$ of the incorrect answers classified with a high level of clarity and $39 \%$ with a low level of clarity. These results can be an indicator of the fact that the clarity level of the answers may be related to their correctness.

Turning now to the type of justification, of the types of justification that were initially referred to, we found only vague or uninformative answers and answers with the relational type of justification. However, it was found that most of the answers were related to an exclusive use of schemes, something that was not assumed in the previously elaborated list. Thus, it will be necessary to add the type of justification: exclusive use of schemes. This was the type of justification most used by students to solve this problem, as it was found in 42 answers, as shown in Figure 17. 


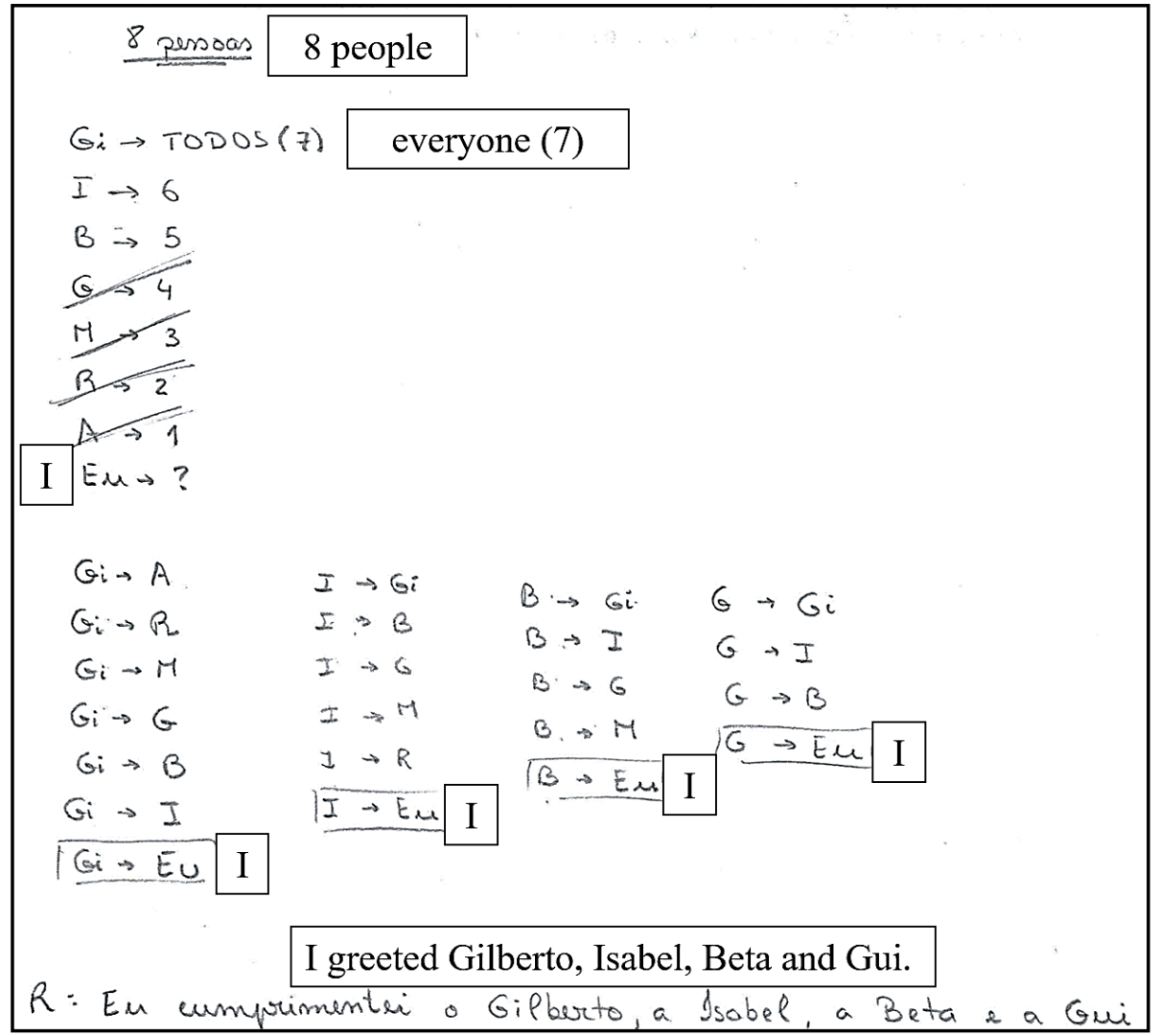

Figure 17 - Problem-solving example with the "exclusive use of schemes" type of justification Source: Research Data - Student A19 (2019)

Responses with the type of justification of exclusive use of schemes are similar to what we see in Figure 17, although schemes may vary. The students draw up their scheme and then write their conclusion without further explanation.

The second type of justification most often presented was the relational one, with about $30 \%$ of responses. The answers with this type of justification, present a justification of all their deductions and steps, and still present the relationship between the different steps, as shown in Figure 18. 


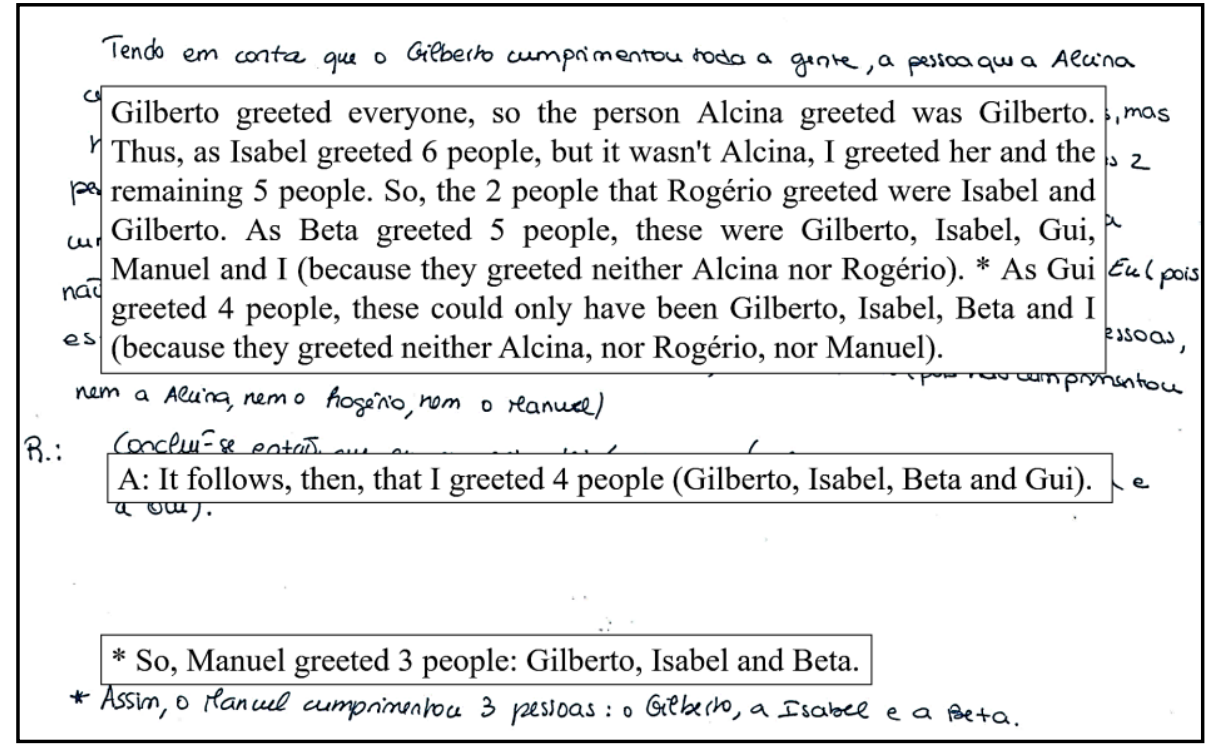

Figure 18 - Problem-solving example with the "relational" type of justification Source: Research Data - Student A20 (2019)

In Figure 18, we see that the student writes his arguments and makes successive deductions, all related to each other, until reaching the final answer, that is, the conclusion of all reasoning.

Finally, the remaining answers were written with a vague or uninformative type of justification, such as the example in Figure 19.

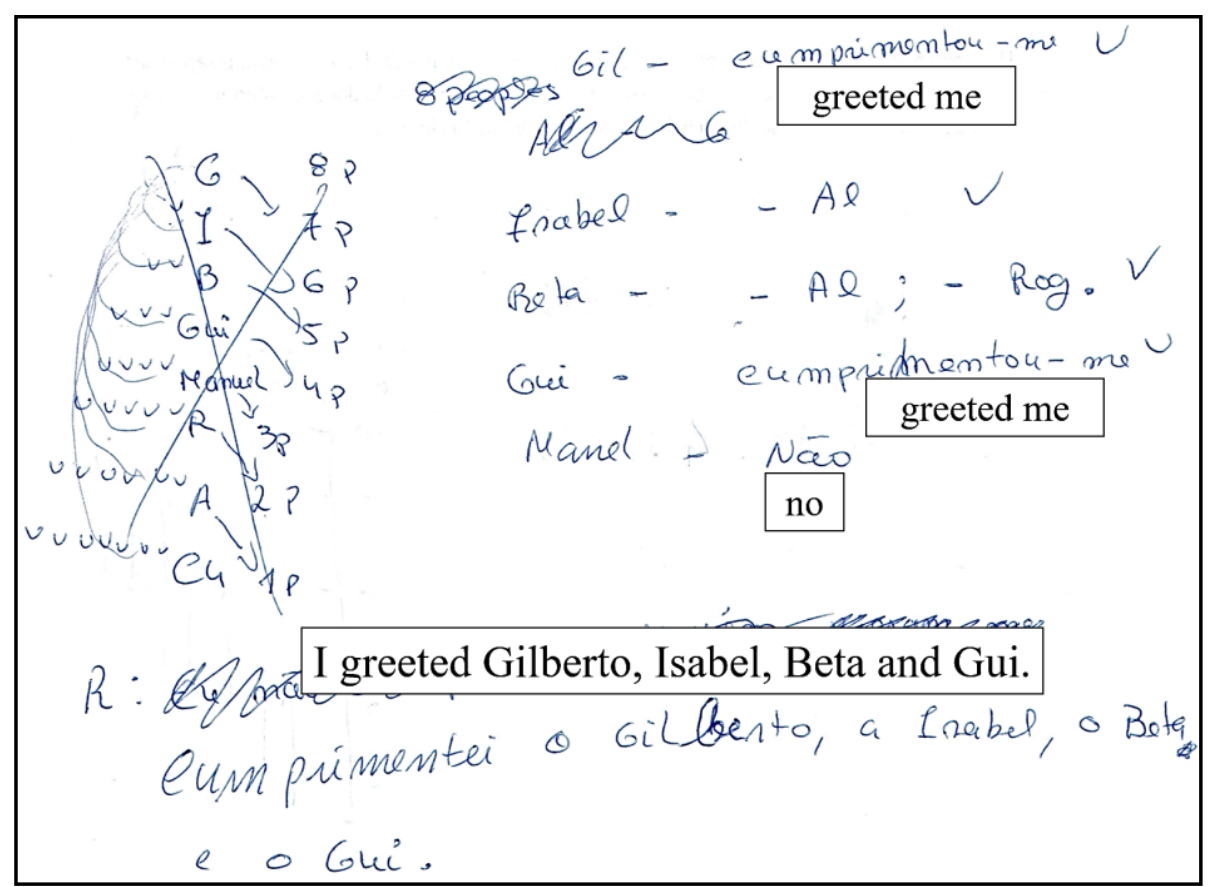

Figure 19 - Problem-solving example with the "vague or uninformative" type of justification Source: Research Data - Student A21 (2019)

In the Figure 19 example, we find an answer that gives us little information about how the student thought, even though the student tried to explain his reasoning in some way. 
Now shifting the focus to the second point of written communication, i.e., the representations used in this problem, there was no responses using the symbolic representation. In fact, this problem also did not encourage this to happen, so it was expected that students would not resort to algebraic symbols to reach a solution. Of the remaining two types of representations, verbal language and iconic representation, there were students who used them exclusively, but there were also those who used both representations at the same time. This simultaneous use was found in about $27 \%$ of the responses, and we can see an example of this use in Figure 20.

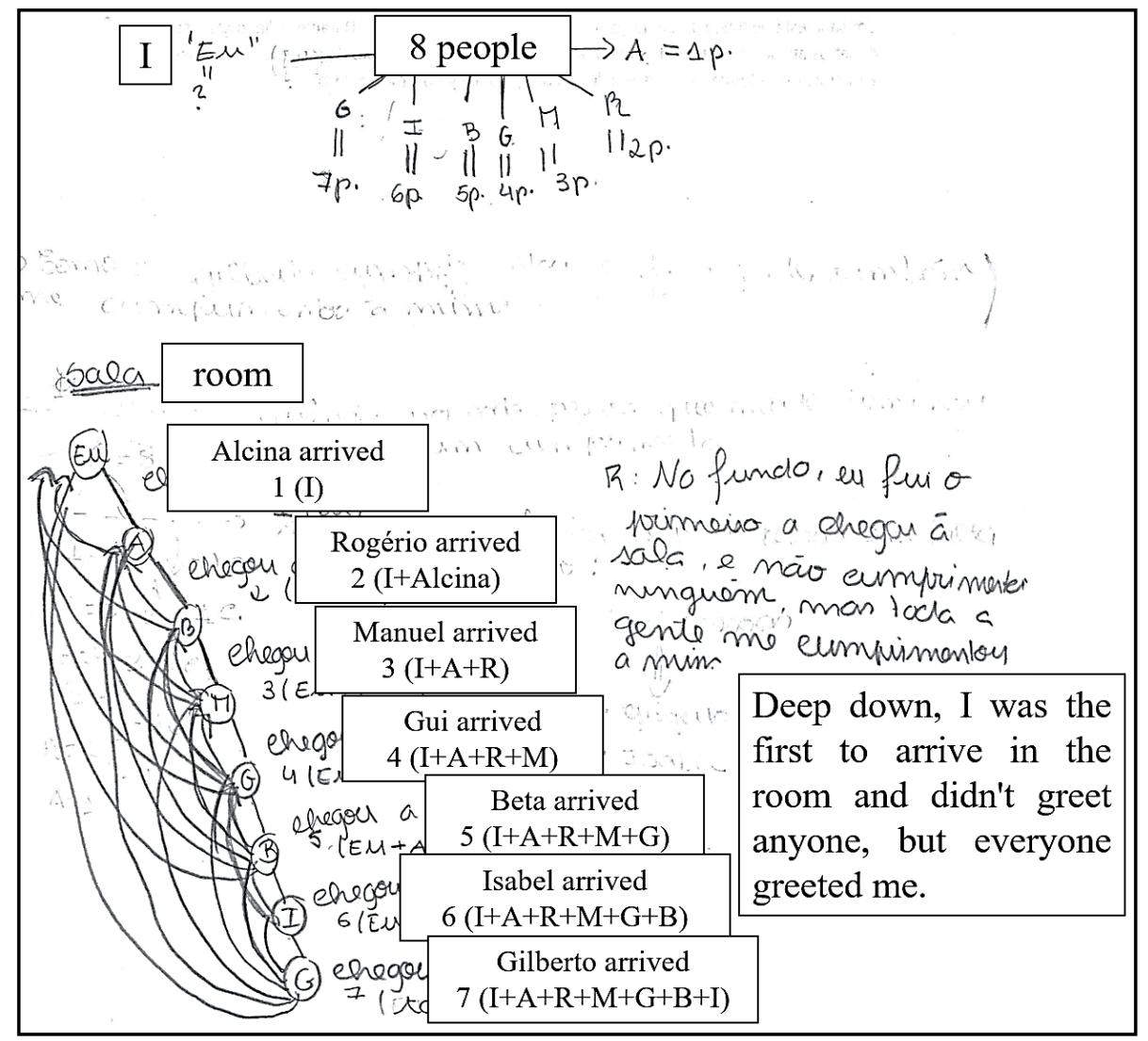

Figure 20 - Problem-solving example using verbal language and iconic representation Source: Research Data - Student A22 (2019)

As we can see in Figure 20, the student used the iconic representation when constructing his scheme, but simultaneously used verbal language to better explain his reasoning.

Of the students who used each representation exclusively, most of them preferred the iconic representation, with 44 students using this type of representation exclusively in their response. In Figure 21, we find the resolution of one of these students. 


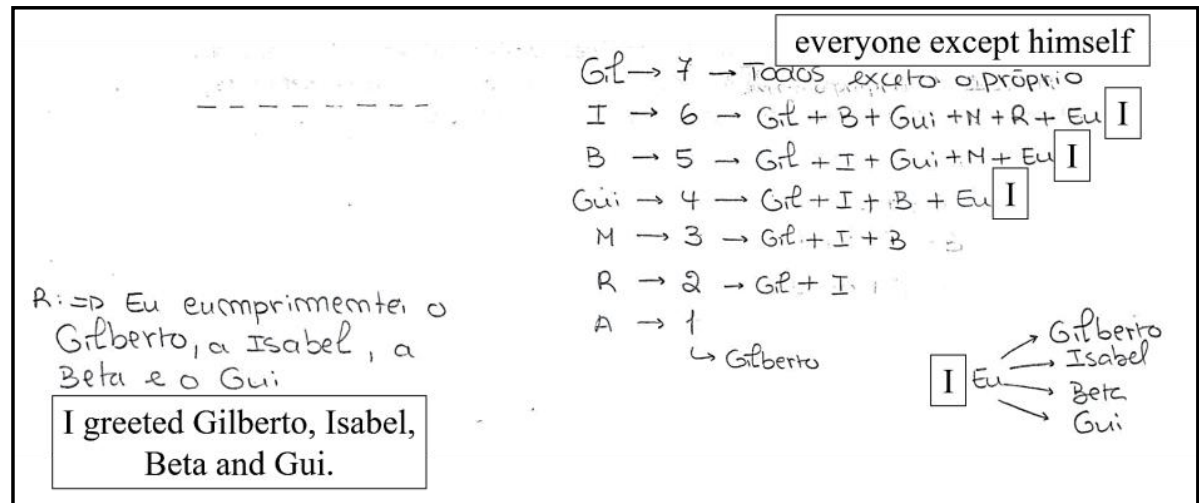

Figure 21 - Problem-solving example with exclusive use of iconic representation Source: Research Data - Student A23 (2019)

In the Figure 21 resolution, we see that the student has made a scheme for structuring his response and, therefore, has resorted to iconic representation. In addition, he clearly used words to write the final answer. However, we are not considering this to be a recourse to verbal language, as it is assumed that the conclusion and formalization of the answer to a problem is always done through a sentence. Thus, we only assume that a student resorted to verbal language when he actually used it throughout the explanation of his reasoning, as in the case of Figure 22.

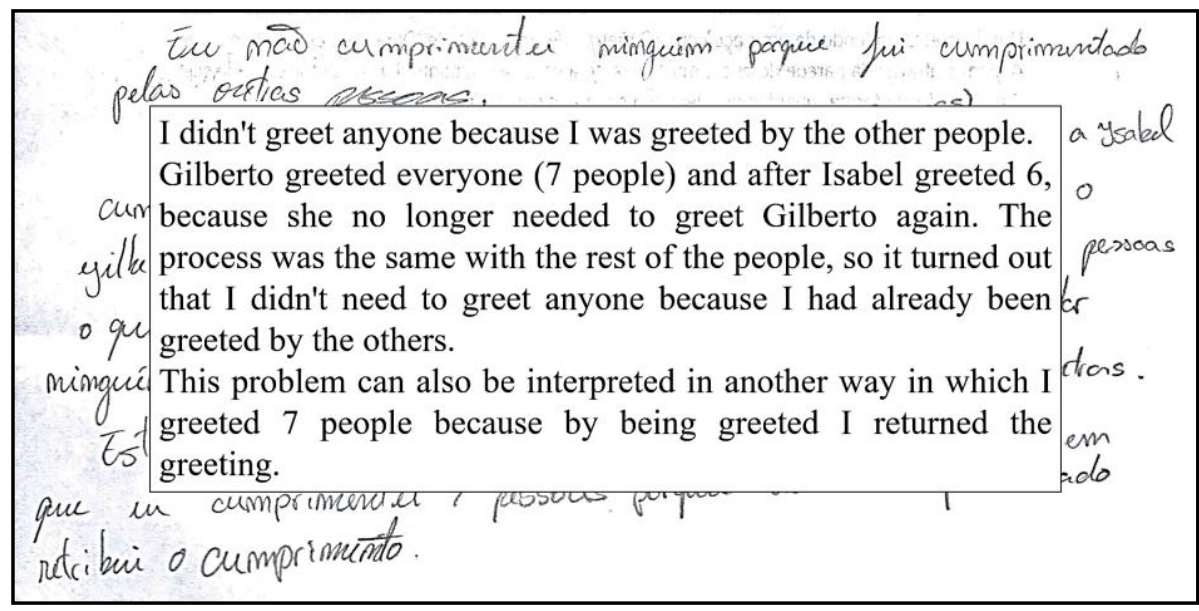

Figure 22 - Problem-solving example using only verbal language Source: Research Data - Student A24 (2019)

The resolution in Figure 22 uses verbal language exclusively to explain the method used to solve the problem. This type of representation was used by 12 of the 85 students.

\section{Concluding remarks}

In this article introduction, the objectives that were intended to be answered were defined as: identifying the problem-solving strategies used by the students, recognizing the difficulties revealed by them, and characterizing the written communication in the presentation 
of their answers. In reaching these goals, we also wanted to see if the strategy used by the students could influence the correctness of their answers, as well as if the level of clarity would have any influence on it.

With regard to strategies, we realized that the strategy most used in the problem that was analyzed was the construction of schemes or figures, which $66 \%$ of students resorted to, and the second most used strategy was deduction, with $28 \%$ of students using it. We also highlight that in six resolutions both strategies were identified simultaneously. In addition to these strategies, the students used two more, albeit with fewer cases: finding a pattern and making tables. These strategies were found in fewer resolutions, as less than $8 \%$ of students used them. Still, we can also add that while making a table was always used exclusively, searching for a pattern was used exclusively by three students, but we found two cases where students used it in conjunction with making a scheme or a figure. We may add that none of the strategies proved $100 \%$ effective, as there were students using similar strategies and getting very different answers and being considered incorrect.

Although it is not possible to define a fully effective strategy, we can see that some strategies may not be as effective as others. While the construction of schemes or figures and the construction of tables resulted in approximately the same number of students arriving at correct and incorrect answers, in the case of the deduction strategy this balance no longer happened. Using this strategy alone, the number of students with incorrect answers almost doubled compared to the number of students with correct answers, which may be an indication that this would not be a very effective strategy to solve the problem. In addition, the finding $a$ pattern strategy was the only one which resulted in only incorrect answers. However, the number of students who resorted to this strategy was very small, which does not allow us to conclude whether or not if it was indeed an inadequate strategy.

In this study, we noticed that the amount of strategies used by the students was lower than those we initially defined. This fact is also mentioned by Biddlecomb and Carr (2011), who report that students have at their disposal several strategies that can be used, some of which are being used more often and others, on the contrary, are seldomly being used.

While in the case of strategies, students used far fewer strategies than those defined in our initial list, in the difficulties, it was necessary to increase what we had initially. It was necessary to add a difficulty within the level of information selection, the difficulty in restricting to the statement data, and yet another level of difficulty, the level of coherence. This need arose because the students assumed data that were neither in the statement nor could be deduced from it and in some responses a lack of coherence was found throughout the reasoning presented, as 
the students began to assume a point of view at the beginning of the answer and in the end already concluded the opposite. Knowing this, regarding the difficulties that could be observed in the answers presented by the students, the most frequent ones were at the level of information selection, more specifically in what concerns in restricting to the statement data, difficulty presented by about $24 \%$ of the students. Still within this level, there were still four students who had difficulties in collecting the statement data and six in organizing the same data. At the strategy level, four students were unable to choose a strategy that would lead them to a solution, and three others had difficulty executing the strategy they had outlined. As for the level of coherence, seven of the 85 students were inconsistent throughout their thinking, which prevented them from reaching a correct solution. Finally, at the persistence level, it was found that two students had difficulty initiating problem solving and four had difficulty completing their answers.

In order to overcome these difficulties, it would help to encourage students to read the statement better and to restrict themselves to the information they derive from it and what they can really derive from it, not by inventing situations that help justify their reasoning. In addition, students should be encouraged to solve more problems, to have more opportunities to internalize different resolution strategies (KLINGLER, 2012), and not to give up trying to solve them in order to counteract the lack of persistence motivated by the excessive habit of exclusively solving exercises (D’AMBRÓSIO, 1989). Although there were few cases of difficulties at the level of persistence, it would be ideal if they did not exist. As for counteracting the lack of coherence in the responses, as well as the difficulty in executing a strategy, students may be encouraged to read their responses in their entirety and to think about them again, to see if everything really conforms to the statement data and what they are really thinking.

Fighting these difficulties can be aided by an incentive to improve the way students communicate in writing, hence the importance of this third element in analyzing student responses to the proposed problem. In this problem, of the 79 students who successfully completed the resolution, all submitted a complete answer. In addition, 34 answered correctly, 3 answered partially correctly - because despite reaching the right number of greetings, they did not specify who was greeted - and the remaining 42 gave an incorrect answer. Regarding the clarity of responses, more than half of the students responded with a high level of clarity, and the medium and low levels were verified in similar amounts of responses, 16 and 18 students, respectively. In addition, by establishing a comparison between the clarity of the answers and their correctness, we realized that the results obtained in this study may be an indicator for the fact that the level of clarity of the answers may be related to their correctness. 
Still regarding the justification of the answers, it was necessary to create a new type of justification, the exclusive use of schemes, and was the type most often used by students when solving this problem, followed by the relational type of justification and, finally, the vague and uninformative answers were found less frequently. At the level of the representations to which the students resorted, none of them used symbolic representation, but the problem neither required this kind of representation nor was there an obvious strategy that could be used to encourage this resource - as happened in the study by Martinho and Rocha (2017). Thus, the representations fell between verbal language and iconic representation, with 12 students using the exclusively the first one and 44 using exclusively the second one. In addition, $27 \%$ of students used both representations simultaneously.

This study aimed to analyze students' problem-solving in three distinct components: strategy, difficulty, and written communication. With the notion of problem clarified and an analysis of these three elements, we hope that teachers will be more willing to bring problems into the classroom, as the citizens of the future are expected to be critical and able to solve problems (OECD, 2018). Thus, it should also be noted again that, although the students solved the problem analyzed individually, at the end of the class they automatically began discussing their ideas about it, which led them to putting argumentation skills into practice and defending their ideas, as well as accepting and understanding other peoples' ideas.

\section{Acknowledgments}

This paper is a result of the project SmartEGOV: Harnessing EGOV for Smart Governance (Foundations, Methods, Tools) NORTE-01-0145-FEDER-000037, supported by Norte Portugal Regional Operational Programme (NORTE 2020), under the PORTUGAL 2020 Partnership Agreement, through the European Regional Development Fund (EFDR). Further support by CIEd - Research Centre on Education, projects UID/CED/1661/2013, UID/CED/1661/2016, UIDB/01661/2020 e UIDP/01661/2020, Institute of Education, University of Minho, through national funds of FCT/MCTES-PT. It also received support from the FCT through a doctoral scholarship (SFRH/BD/147510/2019).

\section{References}

BARDIN, L. Análise de Conteúdo. Lisboa: Edições 70, 1977. 
BAXTER, J. A.; WOODWARD, J.; OLSON, D. Writing in Mathematics: An Alternative Form of Communication for Academically Low-Achieving Students. Learning Disabilities Research \& Practice, v. 20, n. 2, p. 119-135, 2005.

BIDDLECOMB, B.; CARR, M. A longitudinal study of the development of mathematics strategies and underlying counting schemes. International Journal of Science and Mathematics Education, Taiwan, v. 9, n. 1, p. 1-24. 2011.

BILLSTEIN, R.; LIBESKIND, S.; LOTT, J. W. A problem-solving approach to mathematics for elementary school teachers 9. ed. Boston: Adisson-Wesley, 2007.

CASA, T. M. et al. Types of and purposes for elementary mathematical writing: Task force recommendations. 2016. Available at: https://mathwriting.education.uconn.edu/. Accessed in: June 2020.

CASA, T. M. et al. Why Should Students Write in Math Class? Literacy in Every Classroom, v. 74, n. 5, online exclusives, 2017.

COTIC, M.; ZULJAN, M. Problem-based instruction in mathematics and its impact on the cognitive results of the students and on affective-motivational aspects. Educational Studies, v. 35, n. 3, p. $297-$ $310,2009$.

CROSS, D. Creating optimal mathematics learning environments: Combining argumentation and writing to enhance achievement. International Journal of Science and Mathematics Education, Taiwan, v. 7, n. 5, p. 905-930, 2008.

D’AMBRÓSIO, B. S. Como ensinar matemática hoje? SBEM, Brasília, v. 4, n. 2, p. 15-19, 1989.

ESTEVES, M. Análise de Conteúdo. In: LIMA, J. A.; PACHECO, J. A. (Orgs.). Fazer investigação: Contributos para a elaboração de dissertações e teses. Porto: Porto Editora, 2006. p. 105-126.

FREEMAN, B.; HIGGINS, K. N.; HORNEY, M. How Students Communicate Mathematical Ideas: An Examination of Multimodal Writing Using Digital Technologies. Contemporary Educational Technology, v. 7, n. 4, p. 281-313, 2016.

FREITAG, M. Reading and Writing in the Mathematics Classroom. The Mathematics Educator, Georgia, v. 8, n. 1, p. 16-21, 1997.

KANTOWSKI, M. G. Some thoughts on Teaching for Problem Solving. In: KRULIK, S.; REYS, R. E. (Eds.). Problem Solving in School Mathematics. Reston: NCTM, 1980. p. 195-203.

KLINGLER, K. L. Mathematic Strategies For Teaching Problem Solving: The Influence Of Teaching Mathematical Problem Solving Strategies On Students' Attitudes In Middle School. Thesis (Master degree in Education) - College of Education, University of Central Florida, Orlando, 2012.

LESTER, F. Teaching Mathematical Problem Solving. 1987. Available at: http://ncm.gu.se/pdf/namnaren/3243_88_3.pdf. Accessed in: June 2020.

LIMA, J. A. Por uma Análise de Conteúdo Mais Fiável. Revista portuguesa de pedagogia, Coimbra, v. 47, n. 1, p. 7-29, 2013.

LOPES, C. A. Estratégias e métodos de resolução de problemas em matemática. Lisboa: Edições ASA, 2002. 
MARTINHO, M. H.; ROCHA, H. A escrita matemática na resolução de um problema de geometria por alunos de Licenciatura em Educação Básica. In: OLIVEIRA, H.; SANTOS, L.; HENRIQUES, A.; CANAVARRO, A. P.; PONTE, J. P. O ensino e a aprendizagem da Geometria. Lisboa: EIEM, SPCE, 2017, p. 163-177.

MERRIAM, S. B. Qualitative Research: a guide to design and implementation 2. ed. San Francisco: Jossey-Bass, 2009.

NERIA, D.; AMIT, M. Students preference of non-algebraic representations in mathematical communication. In: CONFERENCE OF THE INTERNATIONAL GROUP FOR THE PSYCHOLOGY OF MATHEMATICS EDUCATION, 28, 2004, Bergen. Proceedings of the 28th Conference of the International Group for the Psychology of Mathematics Education. Bergen, 2004. v. 3, p. 409-416.

NEUMAN, W. L. Social Research Methods: Qualitative and Quantitative Approaches 7. ed. Harlow: Pearson Education Limited, 2014.

NOVOTNÁ, J.; EISENMANN, P.; PŘIBYL, J.; ONDRUŠOVÁ, J.; BŘEHOVSKÝ, J. Problem solving in school mathematics based on heuristic strategies. Journal on Efficiency and

Responsibility in Education and Science, Prague, v. 7, n. 1, p. 1-6, 2014.

OECD. Teaching for the Future: Effective Classroom Practices to Transform Education. Paris: OECD, 2018.

PALHARES, P. Histórias com Problemas Construídas por Futuros Professores de Matemática. In: FERNANDES, D.; LESTER, F.; BORRALHO, A.; VALE, I. (Orgs.). Resolução de problemas na Formação Inicial de Professores de Matemática: Múltiplos Contextos e Perspetivas. Aveiro: Grupo de Investigação em Resolução de Problemas, 1997. p. 159-188.

PHONAPICHAT, P.; WONGWANICH, S.; SUJIVA, S. An analysis of elementary school students' difficulties in mathematical problem solving. Procedia Social and Behavioral Sciencies, United Kingdom, 116, p. 3169-3174, 2013.

PIRES, M. M. S. A diversificação de tarefas em matemática no ensino secundário: um projeto de investigação-ação. Lisboa: APM, 2001.

PÓLYA, G. Mathematical discovery: On Understanding, Learning, and Teaching Problem Solving. New York: John Wiley \& Sons, 1981.

PONTE, J. P. Gestão curricular em Matemática. In: GTI (Ed.). O professor e o desenvolvimento curricular. Lisboa: APM, 2005. p. 11-34.

PONTE, J. P. Problemas de matemática e situações da vida real. Revista de educação, Lisboa, v. 2, n. 2, p. 95-107, 1992.

POSAMENTIER, A. S.; KRULIK, S. Problem-solving strategies for efficient and elegant solutions: A resource for the mathematics teacher. Thousand Oaks: Corwin Press, 1998.

PUGALEE, D. K. Writing, Mathematics, and Metacognition: Looking for Connections Through Students' Work in Mathematical Problem Solving. School, Science and Mathematics, v. 101, n. 5, p. 236-245, 2001.

SANTOS, L.; SEMANA, S. Developing mathematics written communication through expositor writing supported by assessment strategies. Educational Studies in Mathematics, v. 8, n. 1, p. 65-87, 2014. 
SINIGUIAN, M. T. Students Difficulty in Solving Mathematical Problems. International Journal of Advanced Research in Engineering and Applied Sciences, v. 6, n. 2, p. 1-12, 2017.

STEINBRING, H. Mathematical interaction shaped by communication, epistemological constraints and enactivism. ZDM Mathematics Education, Berlin, v. 47, n. 2, p. 281-293, 2015.

STEMLER, S. An Overview of Content Analysis. Practical Assessment, Research \& Evaluation, 7, v. 17. 2001.

STERNBERG, R. J. In search of the human mind. Orlando: Harcourt Brace \& Company, 1998.

TAMBYCHIK, T.; MEERAH, T. S. M. Students' Difficulties in Mathematics Problem-Solving: What do they say?. Procedia Social and Behavioral Sciences 8, United Kingdom, v. 8, p. 142-151, 2010.

VIANA, J. P. Eu e mais sete pessoas na sala. In: VIANA, J. P. Uma Vida Sem Problemas: A Matemática nos desafios do dia a dia. Lisboa: Clube do autor, 2012. p. 96-97.

WINCHELT, L. Communication: A Vital Skill of Mathematics. Action Research Projects. 2009.

Submetido em 15 de Janeiro de 2020. Aprovado em 08 de Março de 2021. 